\title{
Annual and diurnal african biomass burning temporal dynamics
}

\author{
G. Roberts, M. J. Wooster, and E. Lagoudakis \\ King's College London Environmental Monitoring and Modeling Research Group, Dept. of Geography Strand, London, \\ WC2R 2LS, UK
}

Received: 20 June 2008 - Published in Biogeosciences Discuss.: 9 September 2008

Revised: 21 January 2009 - Accepted: 11 March 2009 - Published: 15 May 2009

\begin{abstract}
Africa is the single largest continental source of biomass burning emissions. Here we conduct the first analysis of one full year of geostationary active fire detections and fire radiative power data recorded over Africa at 15-min temporal interval and a $3 \mathrm{~km}$ sub-satellite spatial resolution by the Spinning Enhanced Visible and Infrared Imager (SEVIRI) imaging radiometer onboard the Meteosat- 8 satellite. We use these data to provide new insights into the rates and totals of open biomass burning over Africa, particularly into the extremely strong seasonal and diurnal cycles that exist across the continent. We estimate peak daily biomass combustion totals to be 9 and 6 million tonnes of fuel per day in the northern and southern hemispheres respectively, and total fuel consumption between February 2004 and January 2005 is estimated to be at least 855 million tonnes. Analysis is carried out with regard to fire pixel temporal persistence, and we note that the majority of African fires are detected only once in consecutive 15 min imaging slots. An investigation of the variability of the diurnal fire cycle is carried out with respect to 20 different land cover types, and whilst differences are noted between land covers, the fire diurnal cycle characteristics for most land cover type are very similar in both African hemispheres. We compare the Fire Radiative Power (FRP) derived biomass combustion estimates to burned-areas, both at the scale of individual fires and over the entire continent at a 1-degree scale. Fuel consumption estimates are found to be less than $2 \mathrm{~kg} / \mathrm{m}^{2}$ for all land cover types noted to be subject to significant fire activity, and for savanna grasslands where literature values are commonly reported the FRP-derived median fuel consumption estimate of $300 \mathrm{~g} / \mathrm{m}^{2}$ is well within commonly quoted values. Meteosatderived FRP data of the type presented here is now available freely to interested users continuously and in near realtime for Africa, Europe and parts of South America via the EUMETSAT (European Organisation for the Exploitation of
\end{abstract}

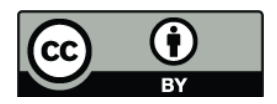

Correspondence to: R. Gareth (gareth.j.roberts@kcl.ac.uk)
Meteorological Satellites) Land Surface Analysis Satellite Applications Facility (http://landsaf.meteo.pt/). Continuous generation of these products will allow the types of analysis presented in this paper to be improved and extended, and such multi-year records should allow relationships between climate, fire and fuel to be further examined.

\section{Introduction}

Biomass burning is a key Earth system process, a major element of the terrestrial carbon cycle and a globally significant source of atmospheric trace gases and aerosols (Hao et al., 1996; Andreae and Merlet, 2001). Depending on their size, location and timing, fires significantly modify land surface properties, influence atmospheric chemistry and air quality, and perturb the radiation budget (Intergovernmental Panel on Climate Change (IPCC), 2001). Millions of square $\mathrm{km}$ of the African landscape are burned each year, and fire in Africa is characterized by strong variability, particularly diurnally and seasonally (Giglio et al., 2006b). African fires are responsible for an average of perhaps 30 to $50 \%$ of the total amount of vegetation burned globally each year, making Africa, on average, the single largest biomass burning emissions source (Andreae, 1991; van der Werf et al., 2003; van der Werf et al., 2006). Burning of biomass is accompanied by a wide variety of characteristic spectral signatures that can be detected by remote sensing, including those related to thermal emissions from actively burning fires, to the albedo and spectral reflectance changes induced by newly burned surfaces, and to the presence of smoke plumes containing trace gas and aerosols in highly elevated concentrations (Trentmann et al., 2002; Jost et al., 2003). For these reasons, and because of the widespread and variable nature of global biomass burning, remote sensing from Earth observation (EO) satellites are considered pivotal to better characterizing the extent and influence of this global phenomenon. So called "hotspot" records of detected actively burning fire locations probably represent the longest duration application of satellite EO in

Published by Copernicus Publications on behalf of the European Geosciences Union. 
the study of biomass burning (Dozier, 1981). Most such studies have relied on data from polar-orbiting satellites, but their restricted overpass frequency, coupled with the diurnal fire cycle, means that the information provided typically represents a limited temporal sample that may not be fully consistent with the need to link emissions estimates to models of atmospheric transport and chemistry (Moula et al., 1996; Wittenberg et al., 1998; Hyer et al., 2007). For these reasons, the potential for using geostationary systems for this purpose has received a significant amount of attention (Prins and Menzel, 1994; Prins et al., 1998; Govaerts et al., 2002; Roberts et al., 2005). In particular, active fire detections derived from the Geostationary Operational Environmental Satellite (GOES) satellite have been used by Reid et al. (2004) and Holben et al. (1996) to parameterize the lower boundary condition of atmospheric process models in order to determine smoke emissions longevity, transport, effects and fate, and despite their relatively coarse spatial resolution $(4 \mathrm{~km}$ at nadir) the GOES-derived active fire data has shown significant impacts on forecasts of atmospheric aerosol loading (Reid et al., 2004).

The Meteosat -8 and -9 satellites of the Meteosat Second Generation system, were launched in 2002 and 2005, respectively, and offer the potential of geostationary active fire detection across Africa, Earth's most fire-affected continent. Both satellites carry the SEVIRI instrument, an imaging radiometer with a $3 \mathrm{~km}$ sampling distance at the subsatellite point and a repeat cycle that provides measurements in eleven spectral channels covering the $0.6-14 \mu \mathrm{m}$ range every $15 \mathrm{~min}$. The reader is referred to Aminou et al. (1997) for a full technical description of SEVIRI, and to Roberts et al. (2005) for an introduction on how the multi-spectral radiance measures it provides can be used to identify the "hotspot" pixels containing actively burning fires. At each such pixel, the rate of Fire Radiative Energy (FRE) release, also called the FRP, can also be retrieved from the instruments infrared radiance measures. FRP is highly correlated to the rate of fuel consumption and thus smoke emissions production (Wooster et al., 2005; Freeborn et al., 2008) and the temporal integration of FRP provides a measure of a fire's FRE, which can be converted to an estimate of total fuel consumption using the linear relations presented in Wooster et al. (2005):

$\mathrm{M}=\mathrm{FRE} \times \beta$

where $\mathrm{M}$ is the biomass combusted $(\mathrm{kg})$, FRE is the Fire Radiative Energy (MJ), and $\beta$ is the radiative fuel consumption factor, estimated as $0.368 \mathrm{~kg} / \mathrm{MJ}$ by Wooster et al. (2005).

This paper concentrates on exploiting the first full year of active fire detections, FRP and FRE data recorded by SEVIRI over the African continent, in order to investigate the seasonal and diurnal cycle of biomass burning in Northern and Southern Hemisphere Africa (NHA and SHA), the pattern and amounts of fuel consumed, and how these vary with land cover. Over selected fires, comparisons are also made to measurements of fuel consumption derived via the alternative burned area based approach, for which data on pre-fire fuel load are estimated from net primary production datasets. Dry matter fuel is $\sim 48 \%$ carbon, and such data on biomass burning carbon emissions maybe of relevance to the information requested by the United Nations Framework Convention on Climate Change (UNFCCC), to which the majority of African countries are signatories (Braatz et al., 1995). Currently, African nations are unable to readily benefit, either financially or technologically, from emissions mitigation schemes implemented under the Clean Development Mechanism (CDM) of the Kyoto Protocol, which focus primarily on more easily quantified industrial emissions from fossil fuel burning (Williams et al., 2007). Improved quantification of other carbon sources (and sinks), and how these might be made to vary with altered land use practices for example, may offer the potential to enable African nations to derive improved benefits in future.

\section{Dataset description and continental scale fire dynamics}

The data used in this work were produced via application of the fire detection algorithm recently described in Roberts and Wooster (2008) to SEVIRI level 1.5 imagery covering February 2004 to January 2005 (the data for January 2004 still being part of the SEVIRI instrument commissioning phase). Figure 1 shows the spatial and temporal pattern of fires across the African continent, derived from the more than $35000 \mathrm{im}$ ages processed as part of this study. It is apparent that in NHA, burning occurs primarily in the Sahel, and moves from the northern to the Southern Sahel between November and February, whilst in SHA fires occur primarily between June and October, generally moving from the northeast to southwest of this hemisphere. Fires are much less common in the equatorial areas of the "woodland" landcover class, which is dominated by generally moist tropical forest that is resistant to burning when in an undisturbed state (Bucini and Lambin, 2002).

Notable exceptions from the gross patterns apparent in each hemisphere occur in NHA in Algeria and Morocco, where fires are evident in June and July in agricultural areas close to the coast. There are also some fires in the interior of Algeria at this time, mixed with signals from oil and gas refineries. In SHA, South Africa also displays a longer fire season than most other areas, with some degree of burning occurring throughout the year.

Three months (February, May and August) of the SEVIRIderived dataset shown in Fig. 1 were compared in detail to active fire data derived from the polar orbiting Moderate Resolution Imaging Spectroradiometer (MODIS) sensor, in order to quantitatively understand the geostationary dataset uncertainties. Being of a significantly higher spatial resolution 


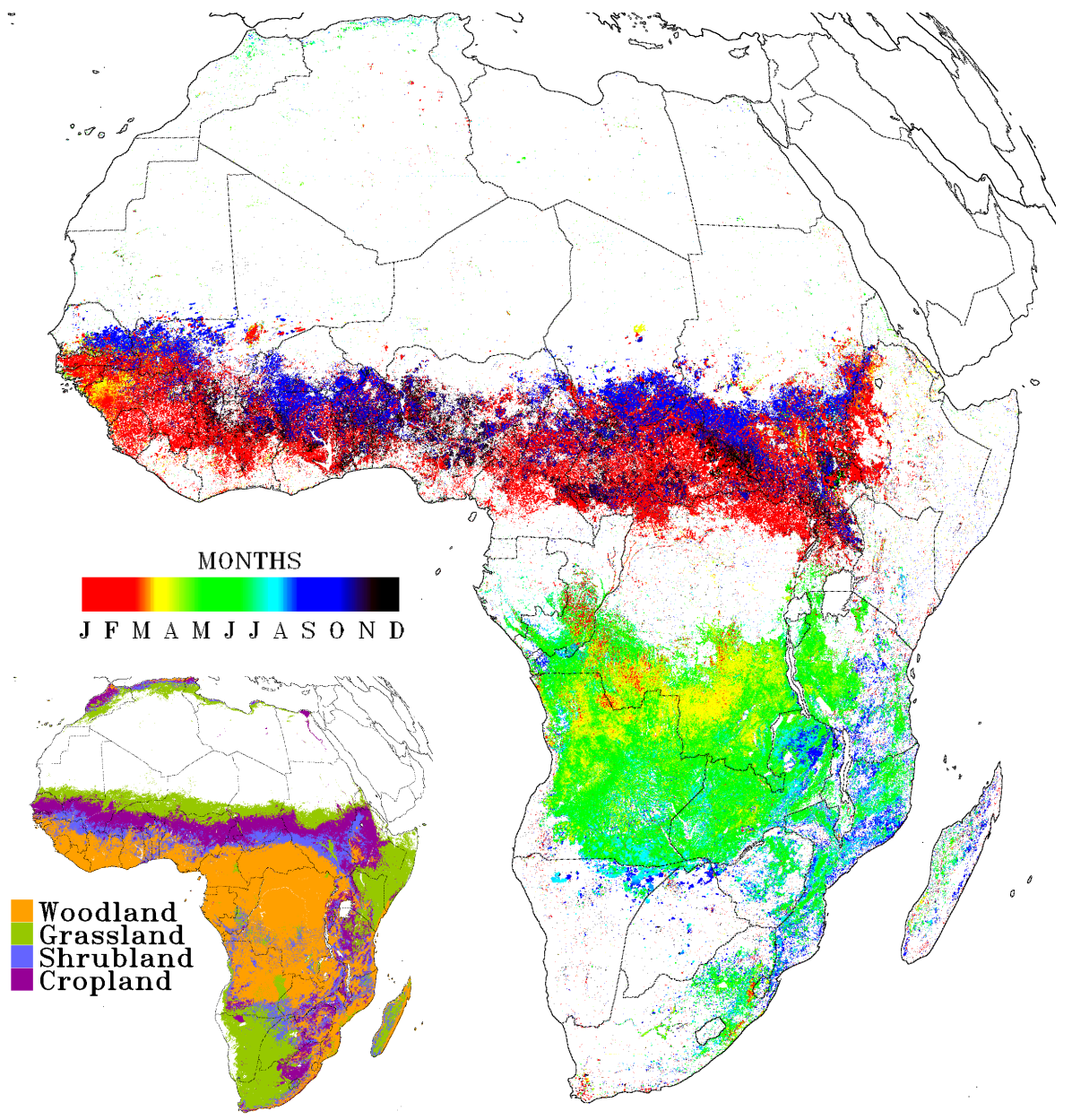

Fig. 1. Geostationary active fire detections over Africa for 2004, colored by day of detection. Multiple fires in the same grid cell are given the date of the last 2004 burning event. Inset map: Global Land Cover 2000 land cover map aggregated into four broad land cover classes.

( $1 \mathrm{~km}$ at the sub-satellite point), and with a wide dynamic range Mid Infrared (MIR) spectral channel, MODIS is well suited to act as a reference sensor for the SEVIRI FRP measures, and this comparison is reported in detail in Roberts and Wooster (2008). A short summary repeated here due to its relevance for the interpretations made in the current study. Figure 1 shows that over these three months, African fire activity is extremely widespread and traverses the entire continent, and the comparison between the geostationary and polar-orbiter derived active fire datasets indicates that SEVIRI has a false alarm rate of $6-8 \%$ in terms of detected fire pixels, with these misclassified fire pixels being responsible on average for only 4-6\% of the total per-scene FRP. This false alarm rate is comparable to that of other active fire detection products where such error statistics have been assessed and published (e.g. Giglio et al., 2003; Feltz et al., 2003). Neither SEVIRI nor MODIS can detect fires through thick meteorological cloud, though fortunately cloud cover is minimized during the African fire season in both hemi- spheres. When a fire is detected near contemporaneously ( $\pm 6 \mathrm{~min}$ ) by both SEVIRI and MODIS, the FRP measures from each sensor show a high degree of agreement $\left(r^{2}=0.87\right.$, $p<0.0001)$, despite the time difference. Thus, provided that a fire is large and/or sufficiently intensely burning to be detectable from geostationary orbit, which only requires that the actively burning fire covers between $0.1 \%$ and $0.01 \%$ of a pixel (Wooster et al., 2005), then SEVIRI should provide a measure of its radiative energy emission rate suitable for estimating its fuel consumption. Summing the FRP detected from all fires at the regional scale (i.e. $\sim 1 / 3$ of the African continent), SEVIRI underestimates total FRP compared to MODIS (Roberts and Wooster, 2008). Two parameters fundamental to a sensor's ability to detect and characterize fires are the minimum detectable fire size and minimum measurable FRP, and the maximum fire size and FRP observable without sensor saturation. These are primarily controlled by the sensor's MIR channel saturation temperature, Instantaneous Field of View (IFOV) and spectral response 
function. SEVIRI's MIR channel saturates at $335 \mathrm{~K}$, resulting in an underestimation of FRP over the largest and/or most intense fires, but this occurs in less than $1 \%$ of the total number of fire pixels detected in the level 1.5 SEVIRI data over Africa (Roberts and Wooster, 2008). The greatest cause of total FRP underestimation is rather the omission of low intensity/smaller fires, that remain undetected by the coarser spatial resolution geostationary sensor but which can be detected by MODIS. The degree of FRP underestimation varies spatially and temporally (Freeborn et al., 2009), however Roberts and Wooster (2008) indicated that it is relatively stable given sufficiently wide integration periods, and all continental-scale FRE values presented herein have therefore been adjusted for these effects where stated.

For the purposes of this study the raw SEVIRI-derived active fire data were gridded to a $1^{\circ}$ resolution and adjustments made for both missing (small or low intensity) fires incapable of being detected by SEVIRI, and the percentage cloud-cover within each grid cell that can potentially mask fires from view, the corrections being made using the methods reported in Roberts et al. (2005) and Roberts and Wooster (2008). The FRP measures were corrected for atmospheric attenuation using the MODerate resolution atmospheric TRANsmission (MODTRAN) v4.0 radiative transfer code (Berk et al., 1999), parameterized using a tropical atmospheric profile and with water vapor concentration derived from threehourly re-analysis data provided by the European Center for Medium Range Weather Forecasting (ECMWF) interpolated to the SEVIRI temporal frequency. Surface height estimates from the GTOPO30 digital elevation model (DEM) and a $23 \mathrm{~km}$ visibility were also assumed in the MODRTAN parameterization.

Using the gridded FRP data, Fig. 2 illustrates the temporal dynamics of biomass consumption across Northern and Southern Hemisphere Africa. May and October represent the times of transition between burning in NHA and SHA, and burning is overall weakest at these times due to the shift in wet and dry seasons between hemispheres. In NHA, peak burning occurs in January where up to $9 \mathrm{Tg}(9$ million tonnes) of biomass burn each day, whilst in SHA burning peaks in July at $6 \mathrm{Tg}$ per day. The mean daily combustion rate of biomass over Africa is $2 \mathrm{Tg}$ (observed) and $2.3 \mathrm{Tg}$ (cloud-cover weighted). The impact of the cloud cover correction actually varies significantly between seasons and hemispheres, becoming more significant on either side of the dry season (a time when absolute biomass burning activity is reduced). The minimum $(<1 \%)$ and maximum $(40 \%)$ daily correction factors occur in the dry and wet seasons, respectively in both hemispheres.Schroeder et al. (2008) found that using the same cloud-cover adjustment approach assumed here for the Amazon region resulted in an overestimation of the number of fire pixels, and indeed fires are not expected to be more prevalent under clouds than under clear skies. Therefore we believe that the cloud-cover weighted data provided here represent a maximum estimate

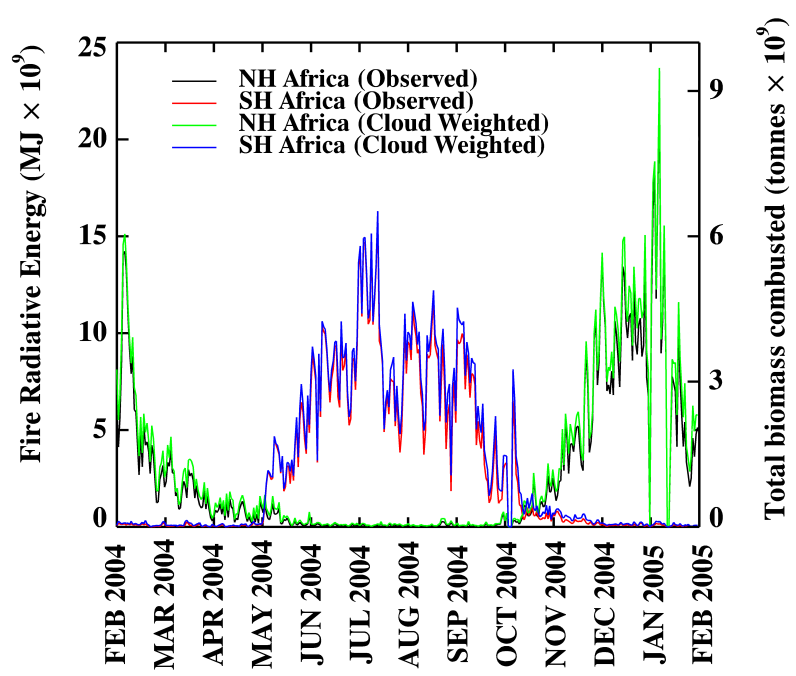

Fig. 2. Temporal dynamics of daily FRE release for Northern Hemisphere (NH) and Southern Hemisphere (SH) Africa, together with the equivalent daily amount of biomass that must be combusted to release that energy, calculated using Equation 1 as detailed in Wooster et al. (2005). Observed and cloud-cover weighted data are shown and these data have been corrected for atmospheric effects and for missing small/low intensity fires.

of total FRE that would have been observed in the absence of clouds (and thus a maximum fuel consumption measure), whereas the observed FRE represents a minimum estimate.

Estimates of the total amount of biomass consumed by fire in NHA and SHA are $414 \mathrm{Tg}$ and $440 \mathrm{Tg}$, respectively using cloud weighted observations (biomass combusted estimates using uncorrected observations are $362 \mathrm{Tg}$ and $402 \mathrm{Tg}$, respectively). The marginally greater amount consumed in SHA mirrors the findings of van der Werf et al. (2006), who also determined that whilst a larger area is burned in NHA $\left(129 \times 10^{4} \mathrm{~km}^{2}\right.$ as compared to $75 \times 10^{4} \mathrm{~km}^{2}$ in SHA) the generally greater fuel loads in SHA result in increased overall fuel consumption. The total $855 \mathrm{Tg}$ FRE-derived continental scale estimate for total fuel consumption is, however, significantly lower than that derived by certain bottomup emissions inventory schemes. Based on a combination of MODIS fire "hotspot" detection and modeling, van der Werf et al. (2003) estimate the fuel consumption to be approximately three times the FRE-derived estimate for 2004, whilst, Lehsten et al. (2008) used burned area estimates and the SPread and InTensity of FIRes and Emissions (SPITFIRE) model to estimate a total consumption of $1400 \mathrm{Tg}$ for the same period. Estimates for the year 2000 made by Ito and Penner (2004) are even higher at between 1824 and $2705 \mathrm{Tg}$. However, lower figures also exist, such as for the peak period of burning (May-October) in SHA where Scholes et al. (1996) derived an estimate of 90-264 Tg and Korontzi et al. (2004) $174 \mathrm{Tg}$ (April-October). Over the same time- 
A

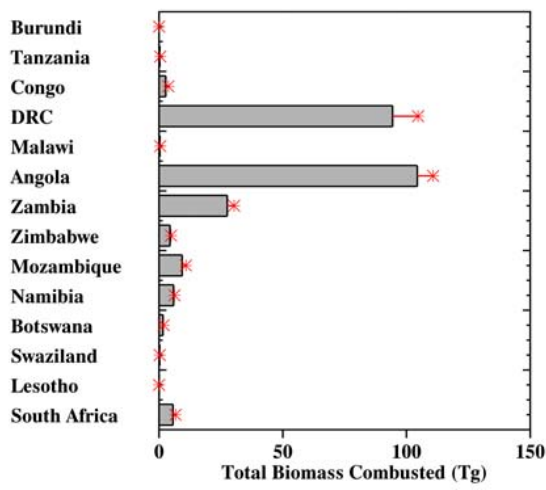

B

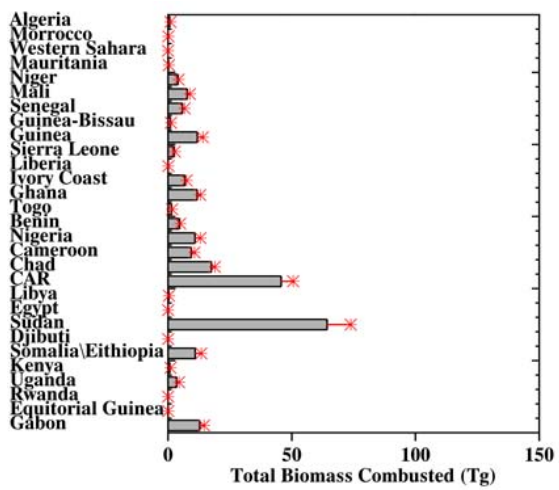

Fig. 3. Total amount of fuel burned in open vegetation fires in countries in (a) Southern Hemisphere, and (b) Northern Hemisphere Africa. Data were derived using the geostationary fire detections and FRE measurements shown in Figs. 1 and 2. Whiskers (red) indicate values after the correction for cloud obscuration. Countries not shown had no substantial fire detections. Note: unlike the continental scale fuel consumption totals in Fig. 2, these per-country fuel consumption estimates are uncorrected for the impact of undetected small/low intensity fires since the spatial scale of these country-wide measures maybe too small to apply the regionally-derived adjustment.

frame (albeit different years), the FRE-derived estimate is 263-290 Tg (observed vs cloud-weighted FRE), which is in reasonable agreement with the upper bounds of these other estimates. Therefore considerable uncertainty still remains as to the true fuel consumption magnitude experienced across Africa, but the FRE approach is the only method to directly relate fuel consumption to a directly observable variable (i.e. the radiant heat released by burning) and thus it provides an important point of comparison to the model-based methodologies available as alternatives.

Figure 3 presents a first annual country-by-country analysis of total biomass consumption across Africa derived via the FRE method. Across NHA burning appears relatively evenly distributed, with Central African Republic (CAR), Chad and Sudan the greatest sources (20-65 Tg of fuel burned in each). In SHA the vast majority of burning occurs in Angola, Democratic Republic of Congo (DRC) and Zambia (26-100 Tg burned each). The magnitude of the cloud cover correction, already illustrated in Fig. 2 is seen to be largest over DRC, Angola, Sudan and CAR, yet its total impact is still relatively minor.

\section{FRP temporal dynamics and relationship to landcover}

Information on the timing of fires, on the land-cover type affected and on the amount of fuel burned is vital for properly parameterising emissions sources and for linking these sources to models of smoke dispersion and atmospheric chemical transport. For example, earlier dry season fires tend to exhibit more incomplete combustion due to the higher fuel moisture content, and consequently emit a greater proportion of less oxidized products such as $\mathrm{CO}$ than do later dry season events (Korontzi, 2005). Figure 4a presents the temporal profiles of daily FRE and equivalent biomass combustion calculated on a 10-day mean basis, for the four main land cover classes derived through aggregation of the $21 \mathrm{in}$ dividual landcover types of the Global Land Cover 2000 map (GLC2000; Mayaux et al., 2004; shown in Fig. 1). According to this categorization, Northern (and Southern) Hemisphere Africa is 19 (46)\% woodland, 17 (25)\% grassland, 7 (15)\% shrubland, and 12 (9)\% cropland by area. The remaining areas are comprised of either desert or water $(45 \%$ and 5\%, respectively for NHA and SHA). African biomass burning appears dominated by fires in woodland ( $72 \%$ of all fire pixels), followed by shrubland (14\%), cropland (8\%) and grassland (6\%). In NHA, areas of shrubland and cropland experience a short fire season limited to between November and February, when agricultural residue (stubble) is burnt after harvest (Yevich and Logan, 2003). In SHA woodland burning dominates the first half of the dry season (May-July), but becomes less dominant later on (August-October) when burning in shrubland and grassland becomes more significant. This corresponds to the southward movement of fire activity from the south-central African woodlands into the shrublands and grasslands of South Africa, as can be seen in Fig. 1.

Figure $4 \mathrm{c}$ presents the time-series of 10-day mean perpixel FRP to match the data on mean 10-day FRE shown in Fig. 4a. In NHA, around the onset of the main burning season (October/November) there is correspondence between increasing mean per-pixel FRP (Fig. 4c) and the increasing FRE (Fig. 4a). Conversely, from the start of the time-series (February 2004), the mean per-pixel FRP of grassland and woodland tends to increase until the end of the dry season where the magnitudes are maximized (March-April), even 

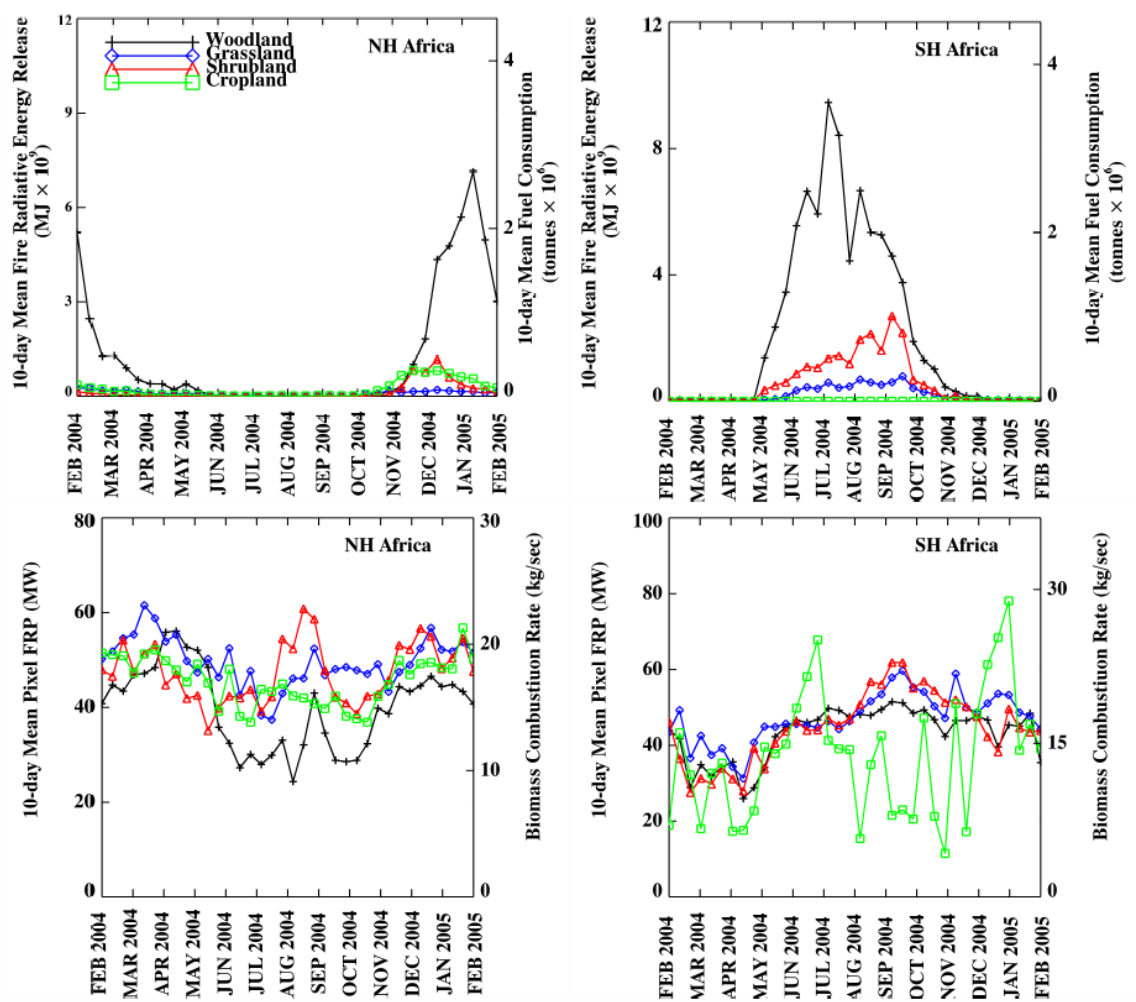

Fig. 4. Temporal dynamics of African biomass burning in the four key land cover classes depicted in Fig. 1, calculated separately for Northern Hemisphere (a and $\mathbf{c}$ ) and Southern Hemisphere (b and d) Africa. Top row shows the 10-day mean FRE release, together with the equivalent amount of biomass that must be combusted to release that energy calculated using Eq. (1) as detailed in Wooster et al. (2005). Bottom row shows the mean FRP per detected fire-pixel, together with the equivalent rate of biomass combustion required to release radiative energy at that rate. Note: since Fig. $4 \mathrm{c}$ and d show per-pixel FRP values, they are not adjusted for the effect of undetected small/low intensity fires as was the FRE data shown in Fig. 4a and b.

though the FRE has already decreased substantially by this time. Between February and April, the mean FRP for shrubland fluctuates before gradually decreasing through the latter part of the dry season. The inference is that there is less fuel being burned at this time compared to earlier in the dry season, but where fires are occurring the combustion rates are high. One reason maybe that much of the available areas of fuel have already been burned by this stage of the season, but what is left has been drying for many months and so burns rapidly and extensively.

The situation is somewhat similar in the Southern Hemisphere (Fig. 4b and d). A gradual increase in the mean FRP is observed between May and September for grassland, shrubland and to a lesser extent woodland. The increasing mean per-pixel FRP values as the dry season progresses are possibly related to decreasing fuel moisture and a resultant increasing combustion completeness. This is consistent with the findings of Hoffa et al. (1999) deduced from experimental burning, where decreasing fuel moisture and increasing fireline intensity were noted as the dry season progressed. Fires in grasslands, shrublands, and to a lesser extent woodlands, have the highest mean per-pixel FRP in September.
Figure 5 details the FRP and fuel consumption data in more detail with respect to a series of more finely resolved land cover classes adapted from GLC2000. Figure 5a records the total amount of fuel burned in each class as derived from the small-fire and cloud-cover adjusted FRP data, whilst Fig. 5b records each class's total surface area as a percentage of African land area. As expected, due to the differing fuel loads, likelihood of ignition and ease of combustibility of fuel between each class, the amount of fuel burned is not simply proportional to the relative class area. Figure $5 \mathrm{c}$ shows the mean, 10th and 90th percentiles of the per-pixel FRP measures for each land cover class. The highly skewed nature of the per-pixel FRP distribution for many classes is evident from the fact that the mean frequently falls towards the bottom end of the distribution. The mean per-pixel FRP shows a $45 \mathrm{MW}$ range (from 20 to $65 \mathrm{MW}$ ) across the classes, and in general it is the land cover classes that would be expected to have higher proportions of herbaceous fine fuels, for example grasslands, that show the greater values. Fine fuels dry most readily and are thus likely to be dominated by flaming combustion and higher combustion completeness. In contrast, forest cover types typically exhibit the lowest 
A

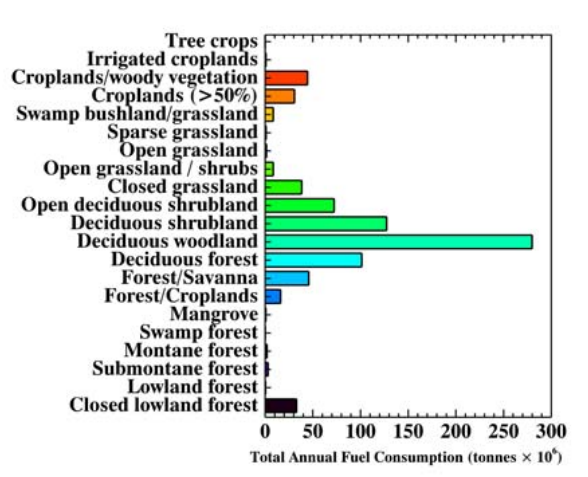

B

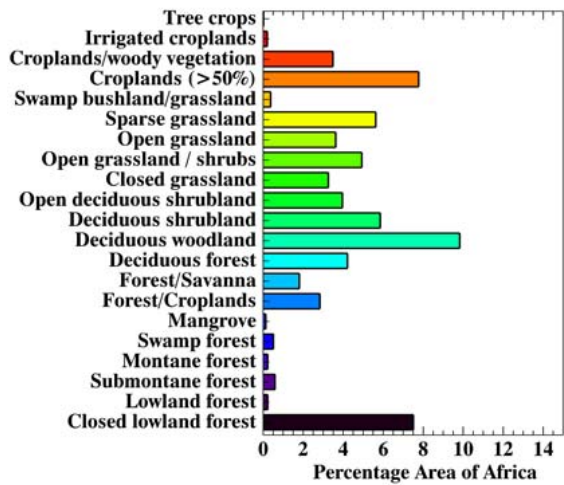

$\mathrm{C}$

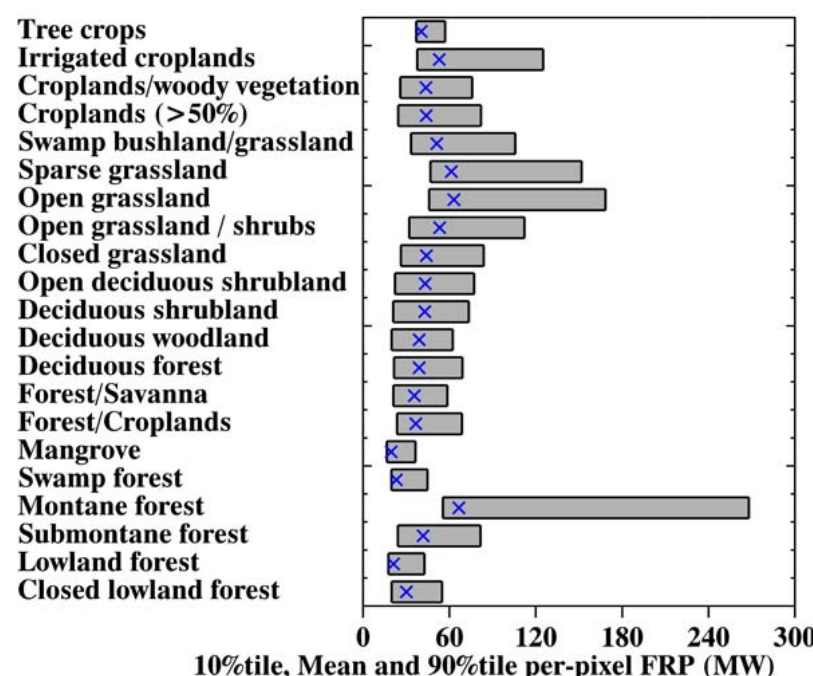

Fig. 5. Biomass burning characteristics of the main fire-affected land cover classes of the GLC2000 database. (a) Total per-land cover class fuel consumption, (b) area of each land cover expressed as the percentage of the total Africa land area, and (c) 10th percentile and 90th percentile (bar) and mean per-pixel FRP (blue cross) of fire pixels detected within each land cover class.

mean per-pixel FRPs, agreeing with the findings of Giglio et al. (2006b) using MODIS-derived FRP measures, and this is likely to be related to the higher fuel moisture content and lower combustion completeness found in forests when compared to senescent grasses. An exception to this occurs in montane forest, where the mean FRP (65 MW) is higher than for the remaining forest cover types. This is due to the greater proportion of fire pixels detected with high FRP magnitudes in this class, and to a lesser extent also in sub-montane forest. Over $95 \%$ of the fire pixels detected in lowland forest had FRP values $<40 \mathrm{MW}$, and $45 \%$ (12 000) of these detections had an FRP of $25 \mathrm{MW}$. Of the fire detections in montane forest, $75 \%$ had magnitudes $<40 \mathrm{MW}$ whilst the remaining $25 \%$ had FRP values of between 40 and $420 \mathrm{MW}$. Analysis of the MODIS Vegetation Continuous Fields (VCF) dataset (Hansen et al., 2003) indicates that the montane forest cover type is composed of an average $48 \%$ shrub/grass cover and $52 \%$ tree cover, values similar to those for the remaining for- est cover types. This similarity in fuel makeup means that the cause of higher mean FRP observations found in montane forest remains unclear.

Figure 6 shows information on fire pixel persistence, calculated as the number of consecutive $15 \mathrm{~min}$. SEVIRI imaging slots that a fire pixel is detected at the same location. To a first approximation, the temporal pattern in the northern and Southern Hemispheres appears to be the inverse of one another, corresponding to durations being greatest during the period of peak burning in each hemisphere, and to the fact that outside of this period the majority of fire pixels are detected in only a single consecutive imaging slot. This pattern of short duration fire pixels outside of the peak fire periods is likely to be related to a combination of factors, (i) fires at this time may indeed last for shorter durations than at peak times due to non-ideal burning conditions; (ii) per-pixel FRPs tend to be lower at these times (Fig. 4) and so more fire pixels approach the limit of detectability from SEVIRI, and thus they 

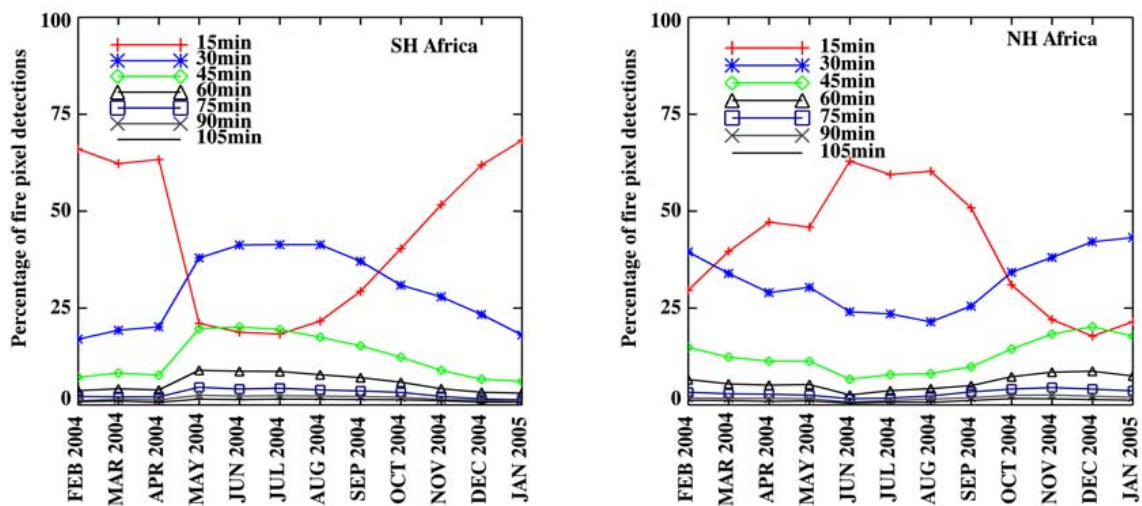

Fig. 6. Monthly temporal active fire pixel persistence in Northern and Southern Hemisphere Africa, calculated from the number of consecutive 15 min SEVIRI imaging slots that a fire pixel is detected at the same location.

maybe detected on one slot but not the next even though they may actually still be burning; and (iii) cloud cover obscuration of fire affected areas increases outside of the main burning periods (Fig. 2) and so may also lead to more intermittent fire pixel detections. It should also be remembered that fires move across the landscape as they consume fuel, and so in any case will not persist in one pixel indefinitely until the fire is extinguished. In addition to fire spread, the geometric stability of the SEVIRI dataset is also important to this analysis. The measured co-registration error of the SEVIRI instrument is typically less than $0.4 \mathrm{~km}$ (at nadir) in both the north-south and east-west directions (EUMETSAT, 2006).

The fact that so many fire pixels across Africa fail to be detected in more than one consecutive SEVIRI imaging slot suggests that temporal filtering of potential fire pixels during the fire detection process is an inappropriate method for minimizing hotspot false alarms in this environment. Fortunately the fire detection algorithm used here and detailed in Roberts and Wooster (2008) avoids this approach, instead relying on a series of detailed spectral and spatial filtering tests. The algorithm used to generate the GOES Automated Biomass Burning Algorithm (ABBA) fire products that cover the America's (Prins and Menzel, 1992; Prins et al., 1998) does use a temporal filter to remove all fires pixels detected only once, but the conditions found over South Americas extensive and highly-cloud affected tropical forest region may make this approach necessary in that case.

\section{Comparison to independent data sources}

In addition to active fire detections, two other types of remotely sensed data sources are commonly used to investigate open biomass burning, namely burned area measures (e.g. Roy et al., 2002; Tansey et al., 2004; Zhang et al., 2003) and trace gas/aerosols column concentrations (e.g. Edwards et al., 2006; Jost et al., 2003). In relation to the current work, both these types of data can provide independent information to which the SEVIRI-derived active fire data can be compared.

\subsection{Measurements of pollution in the troposphere (MO- PITT) CO retrievals}

Liu et al. (2005) previously demonstrated a strong agreement between Advanced Very High Resolution Radiometer (AVHRR) derived active fire pixel counts and MOPITT derived $\mathrm{CO}$ column concentrations over fire-affected regions of North America. However, for Southern Africa a number of researchers have reported a mismatch in seasonality between these types of data. Measured CO amounts and the resultant "top-down" source emissions inventories derived from inverse modeling are reported to peak between August and October in Southern Africa (Pétron et al., 2004; Edwards et al., 2006), whilst emissions derived from fire-count or burned-area driven "bottom-up" schemes, such as the commonly used Global Fire Emissions Database (GFEDv2) of van der Werf et al. $(2003,2006)$ generally peak in July or August (as do the SEVIRI-derived combustion estimates shown in Fig. 2). To demonstrate this disagreement, Fig. 7 provides a direct comparison between $\mathrm{CO}$ concentrations retrieved at five different atmospheric levels from MOPITT, and the SEVIRI-derived biomass combustion estimates for the same period. For SHA, the shape of the CO time series at the lowest atmospheric level $(1000 \mathrm{hPa})$ closely matches that of the SEVIRI-derived FRE profile (Fig. 7a), but with a temporal shift of around two months as has been reported for example in the GFEDv2 vs. MOPITT comparisons discussed above. $\mathrm{CO}$ profiles at the higher atmospheric levels show a similar trend, but with damped amplitude. Swap et al. (2003) proposed that the seasonality discrepancy between such "topdown" and "bottom-up" emissions inventories maybe a result of local meteorological conditions that serve to locally trap and recycle regional smoke pollution. However, Edwards et 
A
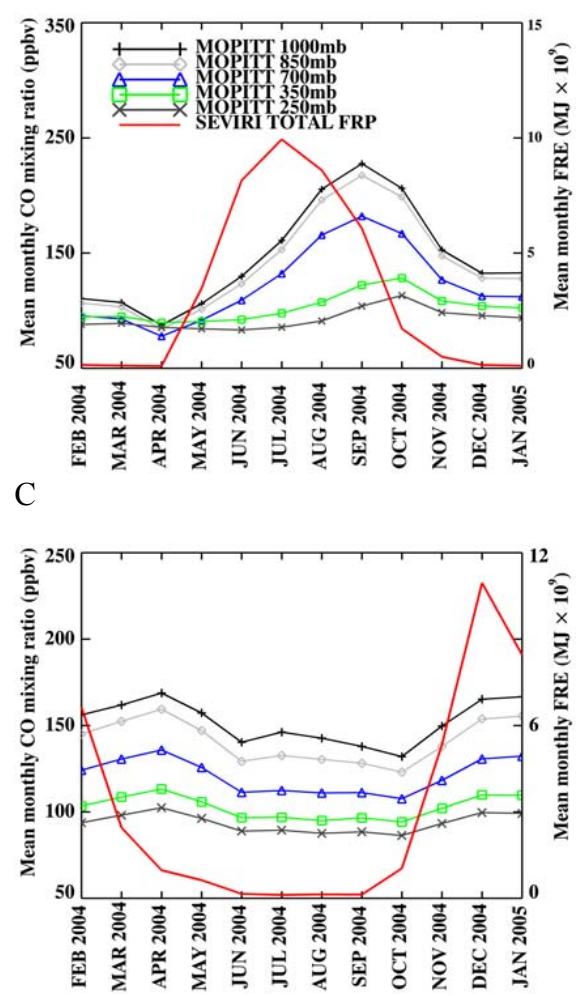

B
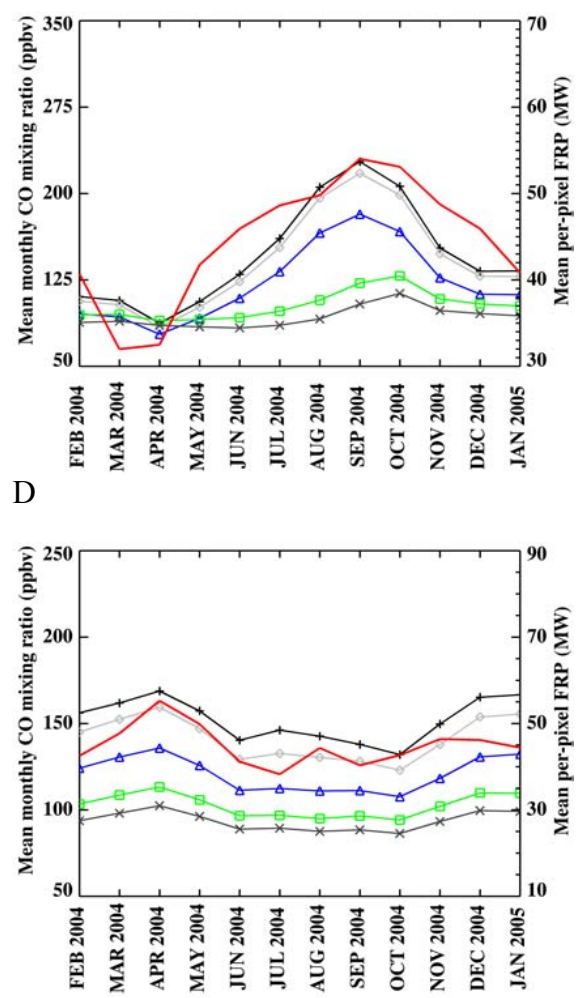

Fig. 7. Comparisons between atmospheric carbon monoxide (CO) concentrations derived from the MOPITT sensor, and SEVIRI-derived biomass burning measures made over Southern (a and b) and Northern Hemisphere (c and d) Africa. CO concentrations were calculated from daytime $1^{\circ} \times 1^{\circ}$ MOPITT level 3 data of cloud-free land areas, with the filtering approach of Hyer et al. (2007) used to screen out CO retrievals where the a priori concentrations were responsible for more than $40 \%$ of the retrieved profile. The SEVIRI-derived variable is shown at left (a and $\mathbf{c})$ as mean monthly FRE, and at right (b and $\mathbf{d})$ as mean per-pixel FRP.

al. (2006) used an atmospheric chemical transport model to demonstrate that three quarters of fire-emitted $\mathrm{CO}$ would be transported out of the region within 8 days of emission, a period too short to explain the much longer seasonality differences observed. As an alternative explanation, van der Werf et al. (2006) suggest the difference may result from increased combustion of woody material towards the end of the dry season. This may in part be supported by the data of Fig. 7b, which indicates that mean per-pixel FRP (which, assuming fuel density remains invariant, could be a potential indicator of combustion completeness) peaks at the same time as the $\mathrm{CO}$ concentration. Figure $4 \mathrm{~b}$ indicates that this apparent southern African combustion completeness maxima is associated with simultaneous peaks in the per-pixel FRP data of grasslands and shrublands, though the former are burning a more significant amount of fuel (Fig. 4a). The agreement between the trends in mean per-pixel FRP (i.e. the mean rate of biomass combustion per SEVIRI fire pixel) and the $\mathrm{CO}$ data suggests that with further refinement such FRP-derived measures might enable better parameterisation of emissions factor temporal evolution over the burning season. For com- pleteness, Fig. 7c and d also illustrates the MOPITT CO and SEVIRI FRP data for Northern Hemisphere Africa. Compared to SHA, the CO concentrations here are rather constant across the year and appear somewhat independent of fire activity.

\subsection{Per-Fire burned area-derived fuel consumption measures}

The analysis here concentrated on a series of individual large fires that burned in the 2004 dry season in southern Africa. Amounts of fuel burned were estimated using the FRE approach, and these were compared to estimates derived from the pre-fire fuel load and a measurement of the post-fire burned area. Fuel loads were calculated from timeintegrated net primary production (NPP) measures (available from http://geofront.vgt.vito.be) derived from Système Pour l'Observation de la Terre (SPOT) VEGETATION (VGT) reflectance imagery and the carbon exchange model of (Veroustraete et al., 1996). Assessment of the post-fire burned area was conducted using MODIS visible channel reflectance 
imagery. The baseline study region for this comparison was selected using a burned area map taken from the ESA Globcarbon project (Plummer et al., 2007). Areas of deciduous woodland, shrubland and grassland that burned during the 2003 Southern African dry season (May-October) were selected as the study zones, assuming that these represent areas where fuel is likely to have been burned nearly completely in 2003 since combustion completeness is stated to vary between 83 and $98 \%$ in such regions (Scholes et al., 1996; Hoffa et al., 1999; Sa et al., 2005). Burned area products are known to miss some fire-affected areas (i.e. errors of omission) but are far less perturbed by errors of commission and so provide a suitable mask for identifying such definitively fire-affected zones (Simon et al., 2004). Assuming therefore that the majority of fuel capable of burning was removed during the 2003 fire events, the NPP data collected during the 2004 subsequent growing season was used to derive the potential fuel load available for the 2004 fire events.

SEVIRI active fire detections were used to identify large fires that burned for between 1 and 5 days in 2004 in the study zones identified by the 2003 Globcarbon burned area mask. Eighteen such fires were identified, and MODIS level 1b NIR reflectance imagery taken immediately before and after each fire at a spatial resolution of $250 \mathrm{~m}$ was used to delineate the burned area of each event following the approach of Smith et al. (2007) that essentially involved temporal differencing and very careful manual interpretation to derive the most accurate assessment available. Derived burned areas for the eighteen ranged from 2 to $40 \mathrm{~km}^{2}$.

At each fire, the pre-fire fuel load was calculated from the SPOT-VGT NPP time-series. NPP measures the production of new terrestrial vegetation, where carbon is allocated to plant stems, leaves and roots, and represents a measure of the difference between carbon uptake during photosynthesis and carbon expenditure during respiration (Fensholt et al., 2006). In the SPOT-VGT NPP product, the reflectance imagery is used to estimate the fraction of absorbed photosynthetically active radiation (fAPAR) at each $1 \mathrm{~km}$ pixel for use in the carbon exchange model of Veroustraete et al. (1996). Estimates of NPP (in units of $\mathrm{gC} . \mathrm{m}^{2}$.d) are provided as 10-day means at the pixel scale via:

$\mathrm{GPP}_{d}=S_{g, d} \cdot \mathrm{fAPAR}_{d} \cdot F_{d} \cdot C$

$\mathrm{NPP}_{d}=\mathrm{GPP}_{d}\left(1-A_{d}\right)$

where $\mathrm{GPP}_{d}=$ daily Gross Primary Production (GPP; $\left.\mathrm{gC} . \mathrm{m}^{2} . \mathrm{d}\right), \quad S_{g . d}$ is the daily incoming solar radiation $\left(\mathrm{MJ} . \mathrm{m}^{2} . \mathrm{d}\right), \mathrm{fAPAR}_{d}$ is derived from the NDVI according to Myneni and Williams (1994), $F_{d}$ expresses the dependency of GPP on incoming solar radiation (unitless), $C$ is a factor (unitless) to account for the dry matter conversion efficiency and $A_{d}$ is the autotrophic respiratory fraction modeled using a linear function of daily mean air temperature (unitless).

The NPP data for each fire was spatially integrated across the 2004 measured burned areas, and integrated temporally

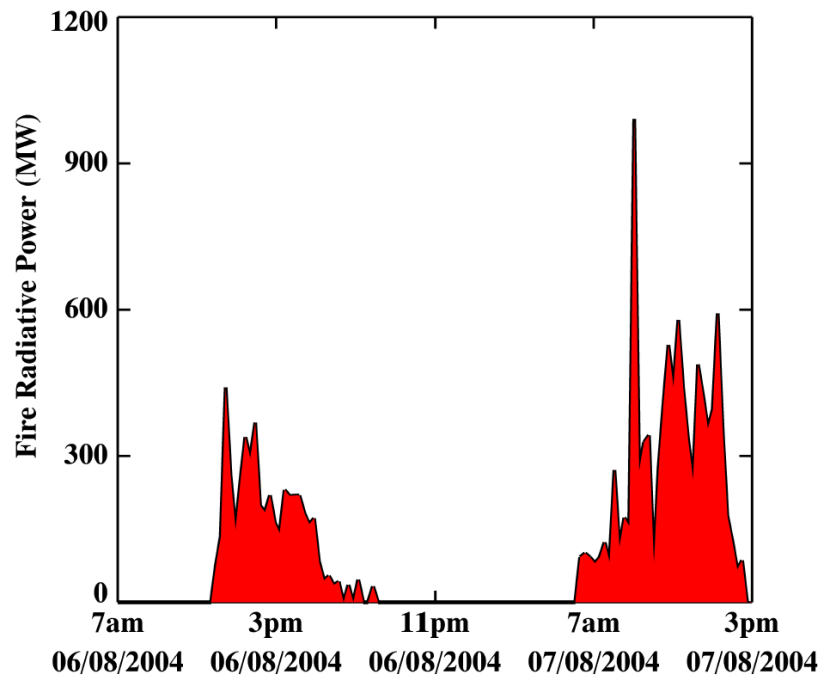

Fig. 8. FRP time series for a single fire that burned on 6th and 7th August 2004 in an area of northern Botswana $\left(26.12^{\circ} \mathrm{E}\right.$, $\left.18.28^{\circ} \mathrm{S}\right)$. The area is classified as sparse grassland according to the GLC2000 landcover map, and FRP at a 15-min temporal resolution is calculated from all fire pixels detected at each SEVIRI time slot. No fire pixels were detected during the evening of 6th August, though it is likely that the fire was in fact still weakly burning due to its appearance once more on the morning of the 7th August.

between the times of the 2003 and 2004 fire events. This provided an estimate of the total available fuel load subject to each of the 2004 fires (in tonnes). Fuel was assumed to be dry matter with a $48 \%$ carbon content, and the calculated fuel load densities for the eighteen fires lay between 129 and $295 \mathrm{~g} / \mathrm{m}^{2}$, with an average of $217 \mathrm{~g} / \mathrm{m}^{2}$. This compares with 267 to $294 \mathrm{~g} / \mathrm{m}^{2}$ for the same areas as recorded in the widely used GFEDv2 database (van der Werf et al., 2003). Fuel consumption estimates for each fire were then made by multiplying the total fuel available by the combustion completeness range of $83-98 \%$ quoted previously.

For comparison to these burned area/NPP estimates of fuel consumption, the time-series of SEVIRI-derived FRP observations were used to calculate total FRE and thus fuel consumption using Eq. 1. An example fire is shown in Fig. 8, where it can be seen that combustion rate is highly variable in time and falls to zero at night. Evidently the fire was actually still burning, but was below the SEVIRI detection limit, since the next day the fire signal returns. Similar diurnal patterns were observed for all fires examined, and during the course of this particular $16 \mathrm{~km}^{2}$ fire, $12 \times 10^{6} \mathrm{MJ}$ of radiative energy was detected by SEVIRI, equivalent to $4400 \mathrm{t}$ of fuel burned. For this fire, pre-fire fuel load was estimated as $420 \mathrm{~g} / \mathrm{m}^{2}$, making the total available fuel mass $6700 \mathrm{t}$. Comparison of the FRE-derived fuel consumption to the pre-fire fuel mass indicates that this fire exhibits on approximately $60 \%$ combustion completeness. Of course, there 


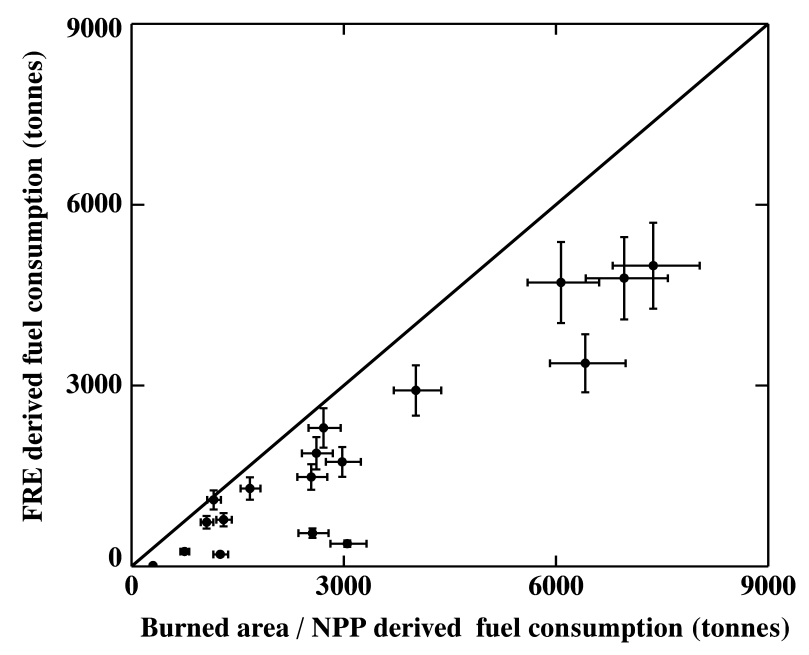

Fig. 9. Estimates of the burned area and NPP-derived total fuel consumption (assuming a 90\% combustion efficiency) and FREderived total fuel consumption for eighteen fires in Southern Africa that burned in August 2004. Error bars on the x-axis are based on the lower (83\%) and upper (98\%) range of combustion completeness values from the literature for these cover types. The error bars on the $y$-axis are taken from the $+/-12.5 \%$ uncertainty in the derivation of FRP according to Wooster et al. (2003).

are uncertainties in the parameterizations made here, including in fire pixel errors of omission and commission, FRP atmospheric correction, burned area and NPP estimation, loss of pre-fire biomass to herbivoury and insects, and the fact that the FRP observations used in this per-fire analysis are uncorrected for the effects of undetected small/low intensity fires. The full set of FRE-derived fuel consumption measures and the NPP/burned area based pre-fire fuel loads are shown in Fig. 9, and these show in general a strong relationship, albeit the fuel consumption estimates are always below the pre-fire fuel load estimates as might be expected given the uncertainties and biases noted above.

\subsection{Continental-scale fuel consumption densities}

In order to examine fuel consumption densities calculated for much larger areas than are covered by the eighteen fires examined in the previous Section, the $1^{\circ}$ gridded FRE-derived total fuel consumption measures were combined with burned area estimates made for the same grid cell and taken from the widely used GFEDv2 database (van der Werf et al., 2003). These burned area measures are in fact derived from a combination of MODIS fire pixel counts and MODIS burned area maps as described in detail by Giglio et al. (2006a). Fuel consumption densities were calculated at a monthly timestep, and recorded for the dominant GLC2000 landcover class within each $1^{\circ}$ grid cell. Results are shown in Fig. 10, and indicate that fuel consumption density generally increases with

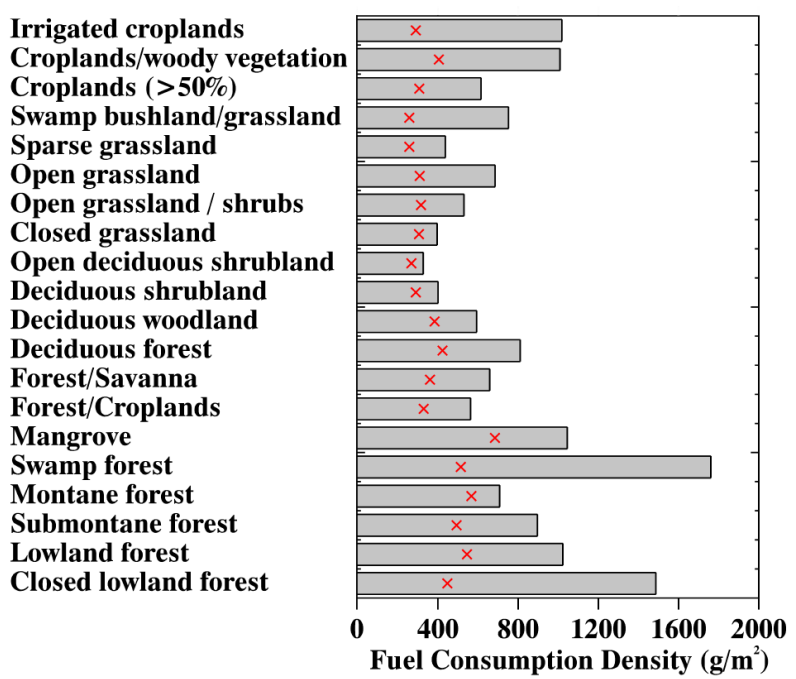

Fig. 10. FRE-derived mean (bar) and median (red cross) estimates of biomass consumption per unit area for different landcover types classified according to the GLC2000 land cover map.

increasing landcover class woody cover - which could indicate the increasing availability of combustible fuel. It is difficult to validate these estimates for all landcover classes, although grassland fuel loads in particular have been quite widely measured and so do provide a point of comparison. From the current dataset the median fuel consumption for savanna grasslands is $300 \mathrm{~g} / \mathrm{m}^{2}$, which agrees quite favorably with literature values: $221-477 \mathrm{~g} / \mathrm{m}^{2}$ (Shea et al., 1996), $296-397 \mathrm{~g} / \mathrm{m}^{2}$ (Govender et al., 2006) and $221-700 \mathrm{~g} / \mathrm{m}^{2}$ (Ward et al., 1996). Tree crops (not illustrated) have a larger fuel consumption estimate $\left(4.5 \mathrm{~kg} / \mathrm{m}^{2}\right)$ than the other cover types. However, there were only 5 grid cells where this cover type dominates, and two of these showed very high estimates of FRE and very low estimates of burned area.

\section{Diurnal biomass burning dynamics}

A great deal of research has been carried out into the spatiotemporal distribution of African biomass burning (e.g. Giglio et al., 2006b; Giglio, 2007; Cooke et al., 1996; Dwyer et al., 2000; van der Werf et al., 2006; Pack et al., 2000). However, with the notable exception of Giglio (2007), Pack et al. (2000) and Ichoku et al. (2008), investigations into fire diurnal variabilities remains rare. This is mostly due the relative difficulty of investigating such variations with polar orbiting sensors. Giglio (2007) has, however, provided a clear indication that a strong diurnal fire cycle does exist across Africa, and that it may vary somewhat across the continent. The most notable feature of geostationary systems is their frequent imaging capability, and this is here exploited to further characterize Africa's diurnal fire cycle at unprecedented temporal resolutions. Understanding of these 

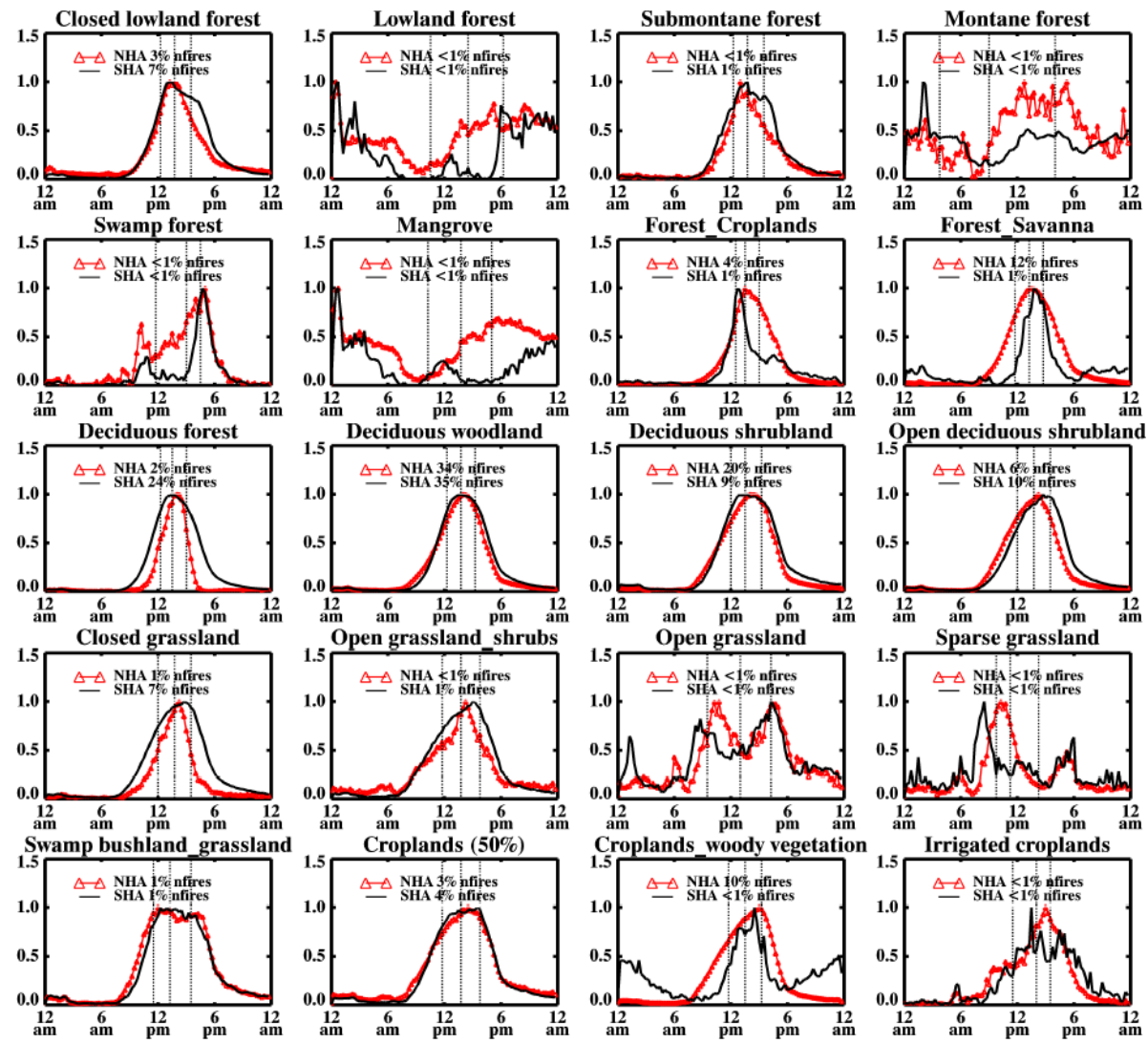

Fig. 11. Normalised diurnal dynamics of fire pixel detections for twenty different land cover types taken from the GLC2000 database. Red indicates results for Northern Hemisphere Africa, black for Southern Hemisphere Africa. All times are local time. The time of the cumulative 25th, 50th and 75th percentiles are marked as vertical dashed lines.

diurnal patterns may help the linking between of fire emissions sources and atmospheric transport models, and might assist in better understanding the mechanisms of land use and land cover change induced by fire. As Giglio (2007) point out, it is also often vital to consider such diurnal variations when considering the sampling biases potentially induced by the use of multiple polar orbiting datasets that may have varying overpass times.

Figures 11 and 12 present, respectively, an analysis of the diurnal cycle of active fire detections and FRP for Northern and Southern Hemisphere Africa. The data were derived using the full 2004 SEVIRI-derived active fire dataset, and are categorized by the GLC2000 land cover class. We follow the method of Giglio (2007), displaying the normalized temporal cycle, and the location of the cumulative 25th, 50th and 75 th percentiles as vertical dashed lines. Figure 11 indicates that a strong diurnal variability exists in fire pixel detections, and for most landcover types this exhibits the form of a skewed distribution with reduced fire activity between around midnight and 07:00 a.m. local time. This is followed by an often rapid increase in fires, peaking around 02:00 p.m. local time. Afternoons are mostly characterized by ever decreasing burning, but with a slope that is less steep than the increase seen in the morning period. Similar active fire diurnal cycle characteristics were noted by Giglio (2007) using data from the low-earth orbiting Tropical Rainfall Measuring Mission (TRMM) satellite. The matching FRP diurnal cycle is shown in Fig. 12, and for most landcover classes closely mirrors that of fire pixel detections. Both parameters typically peak at the same time, although during the afternoon FRP typically decreases at a slower rate than does fire pixel detections. Difference between these parameters is more evident for certain landcover types, for example, swamp bushland/grassland display a decrease in the number of fire detections around midday, something that is not evident in FRP. In most cases the temporal distribution of active fire detections and FRP for a particular landcover type is similar in both hemispheres. However, the temporal dynamics of land cover types with few observations $(<1 \%$ of total fire detections), such as montane forest (NHA), display rather noisy temporal profiles. In the case of lowland forest and mangrove, the results appear biased due to these particular cover types being strongly affected by the build up of daytime cloud cover, such that the retrieved diurnal cycles tend toward the inverse of those of all the other landcover classes.

From the data of Fig. 11 it is clear that there are differences 

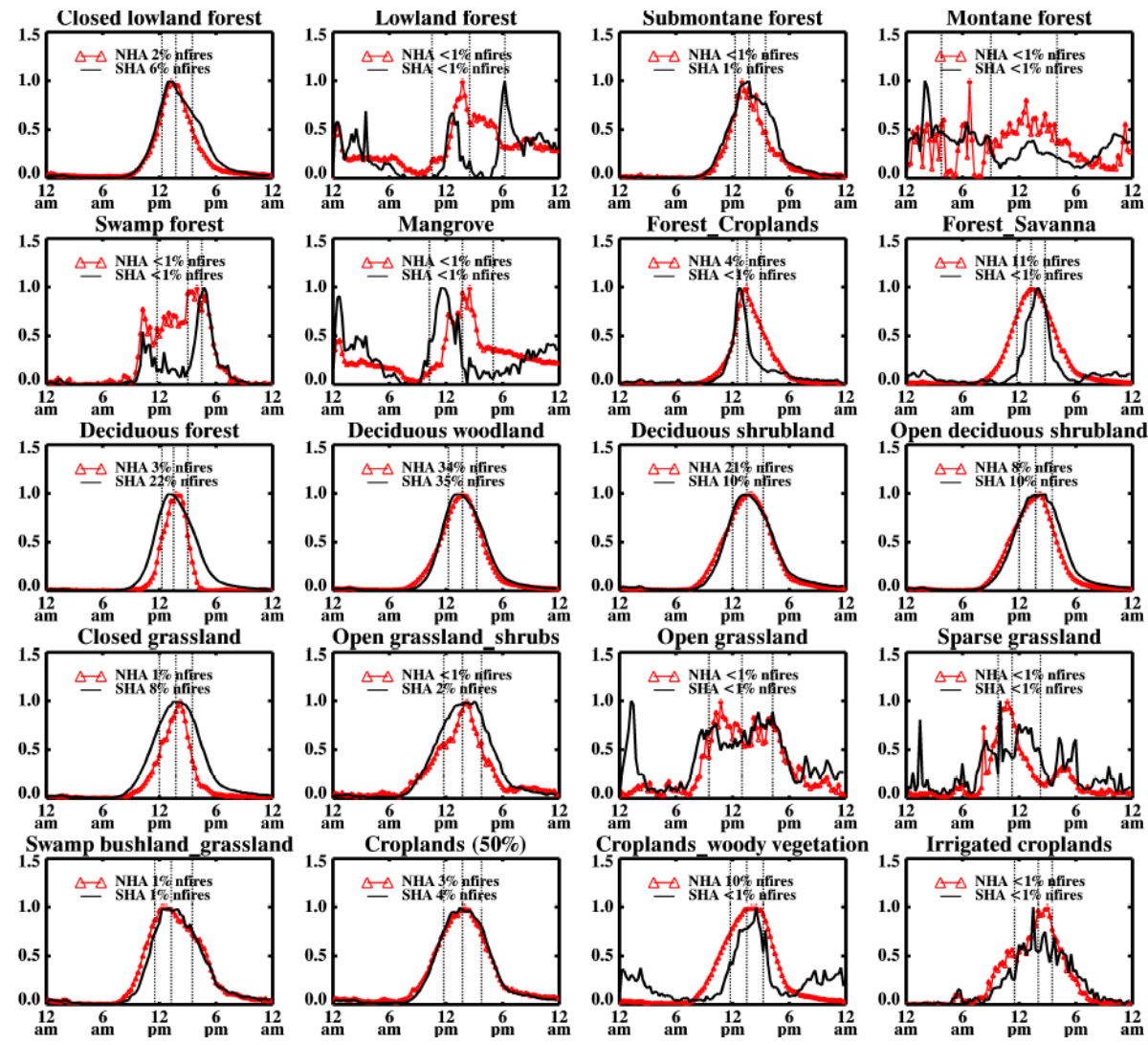

Fig. 12. Normalised diurnal dynamics of FRP for twenty land cover types taken from the GLC2000 database. Red indicates results for Northern Hemisphere Africa, black for Southern Hemisphere Africa. All times are local time. The time of the cumulative 25th, 50th and 75th percentiles are marked as vertical dashed lines.

A

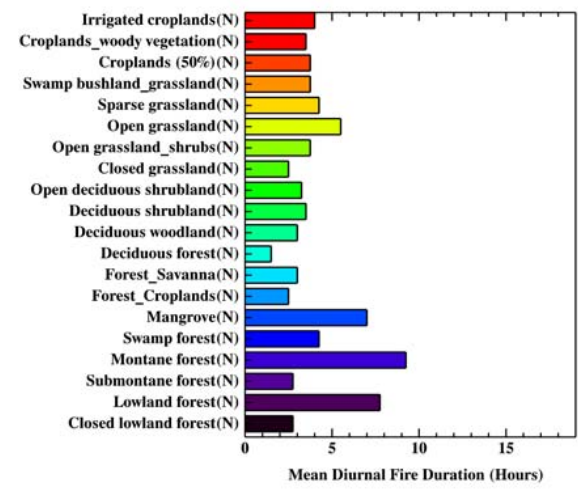

B

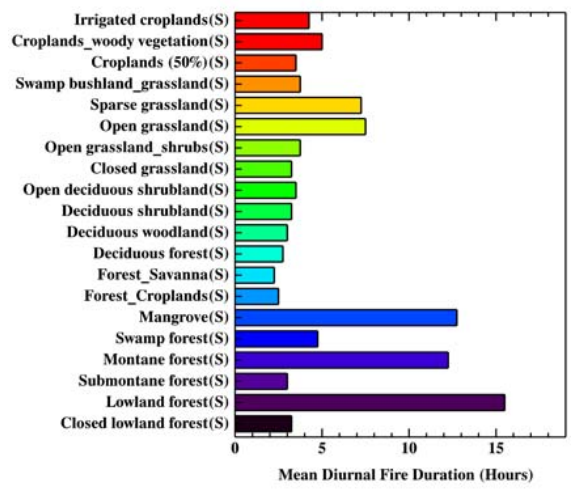

Fig. 13. Mean diurnal duration of fire activity in (a) Northern, and (b) Southern Hemisphere Africa, shown across a series of different major land cover types taken from the GLC2000 database. Fire diurnal duration is defined as the period of time between the 25 th and the 75 th percentiles identified in Fig. 12.

between the diurnal fire cycle of the different broad land cover types (e.g. forest, shrublands/woodlands, grasslands and croplands). These differences were analysed with respect "width" of the diurnal distribution, taken as the 25th and 75th cumulative percentiles of the active fire pixel detections (Fig. 11) and FRP (Fig. 12). The full width at half maximum (FWHM) was not used, since this is more appropriate for properly Gaussian distributions (Giglio, 2007). Results are shown in Fig. 13, and in general most land cover types can be seen to have a diurnal "width" of less than 

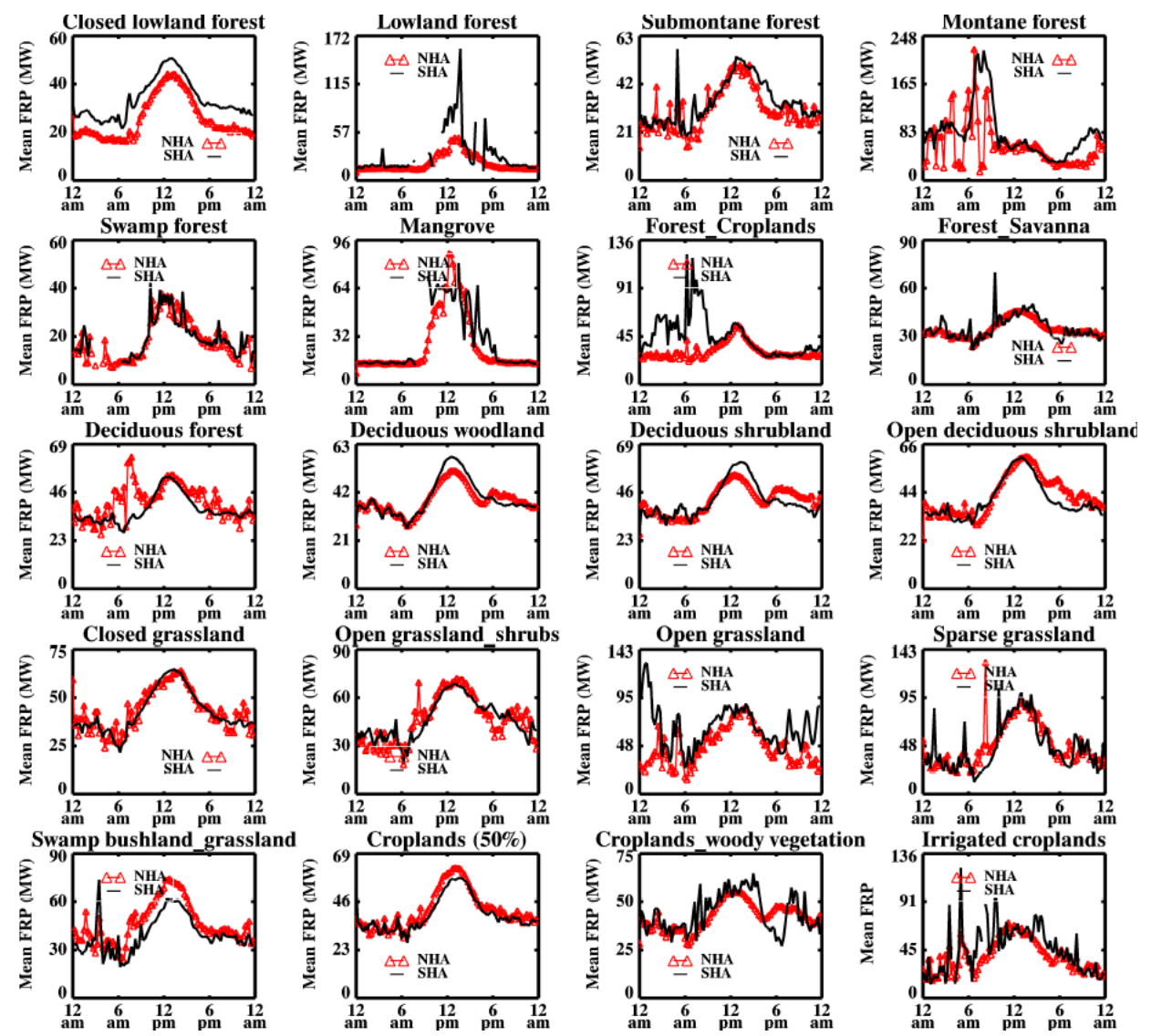

Fig. 14. Diurnal variation in the mean FRP for twenty land cover types taken from the GLC2000 database. Red indicates results for Northern Hemisphere Africa, black for Southern Hemisphere Africa. All times are local time.

$5 \mathrm{~h}$. The narrowest distributions occur for deciduous forest/woodland, shrubland and closed grassland, at between 2 and $4 \mathrm{~h}$. This is consistent with Giglio (2007), who suggest the increased woody fuels can limit the periods of the day when combustion can occur. In contrast, open and sparse grasslands have a more uniformly distributed biomass burning diurnal cycle, with a diurnal width of 4 to $8 \mathrm{~h}$. Such herbaceous cover types contain a high proportion of finer fuels that are capable of drying rapidly, most likely enabling fires to persist in an intense manner for a longer period of the day. The diurnal distribution of biomass burning for the more herbaceous land cover types actually suggests two peaks, particularly so in the case of open grassland where mid-morning and mid-afternoon peaks are separated by a relative dip around midday (Figs. 11 and 12). To some extent this phenomenon has been seen with regard to fire pixel detections in the previous work of Pack et al. (2000) and Giglio (2007), and a possible cause is the specific land management practices followed in both hemispheres and both parts of the day (i.e. reduced burning around midday, possibly due to reduced anthropogenic ignitions). Another possibility is fire detection bias due to the contrast between fire pixels and surrounding non-fire pixels (upon which the fire detection algorithm partly depends; Wooster and Roberts, 2008) being reduced around solar noon. However, since the "twin-peak" phenomena is limited to only one land cover class this may not be a reliable explanation.

Finally, Fig. 14 presents the diurnal distributions of mean per-pixel FRP for each land cover type in the GLC2000 database. For most cover types, the maximum value occurs in the early afternoon, and is typically around twice that found at nighttime. Using polar-orbiting MODIS active fire data, Ichoku et al. (2008) found similar diurnal trends in the mean FRP across most of Africa. Cover types with a greater proportion of herbaceous material typically have the highest per-pixel FRP, consistent with the data of Fig. 5c. Generally, results are similar for both hemispheres, although closed lowland forest and swamp/bushland/grassland are notable exceptions. In these cases, the hemisphere with the greatest number of fire pixel detections in that cover type shows the greatest mean per-pixel FRP. In the case of closed lowland forest, the diurnal profiles are similar with respect to temporal profile. During the day the mean FRP magnitudes are similar although at night the SHA mean FRP is somewhat greater than the NHA. Analysis of the MODIS VCF dataset (Hansen et al., 2003) indicates that the fire pixels in SHA 
closed lowland forest are composed of a greater proportion of shrub/grass vegetation than are those in NHA closed lowland forest (52\% and 35\%, respectively). It is possible that the reduced tree cover in SHA improves the conditions necessary for combustion (i.e. reduced relative humidity, higher temperatures and greater wind speeds), thus enabling more effective combustion and which can continue more at night than in the NHA case.

\section{Conclusions}

We have conducted an analysis of the spatial and temporal dynamics of African biomass burning using the first full year of active fire detections and FRP data available from the SEVIRI radiometer onboard the Meteosat- 8 satellite. These data were calculated from over 35000 individual SEVIRI imaging slots, subject to the fire detection and characterization routines detailed in Roberts and Wooster (2008). Using the geostationary observations, patterns of active fire activity have been quantified on a continental scale and at a temporal frequency previously unavailable for investigation. African biomass burning is shown to involve periods of extreme fuel consumption, but also to be highly variable in space and time. Peak combustion totals are 9 and 6 million tonnes of fuel consumed per day in the Northern and Southern Hemispheres, respectively, but with values close to zero at periods outside of the key dry season characterizing each hemisphere. The fire diurnal cycle is shown to be strong for both hemispheres and for most landcover types, with combustion rates peaking early in the afternoon in most cases and with relatively little combustion at night (at least in terms of that detectable from geostationary orbit). Peak daytime combustion rates in the northern and southern hemispheres reach 170 and $200 \mathrm{t}$ of fuel per second, respectively.

This study also presents some of the first estimates of the amount of vegetation consumed annually by open vegetation burning within each fire-affected African country, calculated using a common and consistent methodology. Over $60 \%$ of the total fuel burned is consumed by fires in Angola, DRC, Sudan and the Central African Republic, and over the continent as a whole we estimate that a minimum of 855 million tonnes of biomass was burned in open vegetation fires in 2004. In both hemispheres, the majority $(86 \%)$ of fire detections occur in woodland and shrublands, with croplands (8\%) and grasslands (6\%) contributing significantly less. Analysis of the temporal persistence of active fire detections indicates that Southern Hemisphere Africa contains a marginally greater number of fires which burn for longer in one place than does Northern Hemisphere Africa, and in both hemispheres the fire pixel persistence increases during the peak of the burning season. However, overall the majority of fire pixels in Africa are detected in the same place only one or two consecutive SEVIRI imaging slots, either becom- ing undetectable between slots or moving into the next pixel due to fire spread.

We have compared the SEVIRI-derived biomass combustion estimates to burned-area based measures, both at the scale of individual fires where there is strong agreement, and over the entire continent at a 1-degree resolution. In the latter case, where there are sufficient grid cells dominated by a single landcover class, the fuel consumption estimates always averaged less than $2 \mathrm{~kg} / \mathrm{m}^{2}$. Over savannas, we calculate median biomass combustion measures of $300 \mathrm{~g} / \mathrm{m}^{2}$, well within $\sim 220-700 \mathrm{~g} / \mathrm{m}^{2}$ range reported in the literature.

In order to be of maximum use to atmospheric scientists and to those involved in modeling carbon-climate interactions, the types of dataset presented here must ideally be extended to include multi-year observations capable of being use to assess interannual variability's and patterns. In part to meet this requirement, the EUMETSAT has instigated a process to operationalise the production of the SEVIRI FRP product, both at the pixel scale and at a reduced spatial and temporal resolution that allow appropriate bias adjustments to be applied for the limitations induced by the non-detection of smaller/less intense fires and by cloud cover. These datasets will be produced at the EUMETSAT Land Surface Analysis Satellite Applications Facility (Land SAF) and the first pre-operational versions are now available for exploitation by users (http://landsaf.meteo.pt/).

Acknowledgements. Support for the development of this dataset came from the NERC Earth Observation Enabling Fund (NE/C5154984/06), from EUMETSAT and from the European Union FP6 "CARBOAFRICA" project. The NERC National Center for Earth Observation (NCEO) supported the analysis developed herein. SEVIRI data were kindly provided under an ESA/EUMETSAT AO. MOPITT and MODIS data were provided by the NASA Langley and EDC DAACS, respectively. The authors would like to thank the referees for the constructive comments that helped to clarify and improve this manuscript.

Edited by: J. Kesselmeier

\section{References}

Aminou, D. M. A., Jacquet, B., and Pasternak, F.: Characteristics of the Meteosat Second Generation Radiometer/Imager: SEVIRI, Proceedings of SPIE, Europto series, 3221, doi:10.1117/12.298084, 1997.

Andreae, M. O. and Merlet, P.: Emission of trace gases and aerosols from biomass burning, Global. Biogeochem. Cy., 15(4), 995966, 2001.

Andreae, M. O.: Biomass Burning : Its history, use and distribution and its impact on the environmental quality and global climate, in: Global Biomass Burning: Atmospheric, Climatic and Biospheric Implications, edited by: Levine, J. S., MIT Press, Cambridge, Massachusetts, 3-21, 1991.

Berk, A., Anderson, G. P., Bernstein, L. S., Acharya, P. K., Dothe, H., Matthew, M. W., Adler-Golden, S. M., Chetwynd, J. H., 
Richtsmeier, S. C, Pukall, B., Allred, C. L., Jeong, L. S., and Hoke, M. L.: MODTRAN4 radiative transfer modeling for atmospheric correction, Proceedings SPIE Optical Spectroscopic Techniques and Instrumentation for Atmospheric and Space Research III, 19-21 July, 3756, 1-7, 1999.

Braatz, B. V., Brown, S., Isichei, A. O., Odada, E. O., Scholes, R. J., Sokona, Y., Drichi, P., Gaston, G., Delmas, R., Holmes, R., Amous, S., Muyungi, R. S., De Jode, A., and Gibbs, M.: African greenhouse gas emission inventories and mitigation options: forestry, land-use change and agriculture, Environ. Monit. Assess., 38, 109-125, 1995.

Bucini, G. and Lambin, E. F.: Fire impacts on vegetation in Central Africa: a remote-sensing-based statistical analysis, Appl. Geogr., 22(1), 27-48, 2002.

Cooke, W. F., Koffi, B., and Gregoire, J-M.: Seasonality of vegetation fires in Africa from remote sensing data and application to a global chemistry model, J. Geophys. Res., 101(D15), 2105121065, 1996.

Dozier, J.: A method for satellite identification of surface temperature fields of sub-pixel resolution, Remote. Sens. Environ., 11, 221-229, 1981.

Dwyer, E., Pinnock, S., Gregoire, J.-M., and Pereira, J. M. C.: Global spatial and temporal distribution of vegetation fires as determined from satellite observations, Int. J. Remote. Sens., 21, 6\&7, 1289-1302, 2000.

Edwards, D. P., Emmons, L. K., Gille, J. C., Chu, A., Attie, J.-L., Giglio, L., Wood, S. W., Haywood, J., Deeter, M. N., Massie, S. T., Ziskin, D. C., and Drummond, J. R.: Satellite-observed pollution from Southern Hemisphere biomass burning, J. Geophys Res., 111, D14312, doi:10.1029/2005JD006655, 2006.

EUMETSAT: Pre-Launch MSG-1 SEVIRI Instrument Level 1.0 Data, Technical Report EUM/OPS-MSG/TEN/05/0625, 1-18, 2006.

Feltz, J. M., Moreau, M., Prins, E. M., McClaid-Cook, K. and B., Irving, F.: Recent validation studies of the GOES Wildfire Automated Biomass Burning Algorithm (WF-ABBA) in North and South America. International Wildland Fire Ecology and Fire Management Congress, 2nd and Symposium on Fire and Forest Meteorology, 5th, Orlando, FL, 16-20 November 2003 (preprints), American Meteorological Society, Boston, MA, International Wildland Fire Ecology and Fire Management Congress, 2nd., Paper P7.3,Call Number: Reprint \# 3893, 2003

Fensholt, R., Sandholt, I., Rasmussen, M. S., Stisen, S., and Diouf, A.: Evaluation of satellite based primary production modeling in the semi-arid Sahel, Remote. Sens. Environ., 105(3), 173-188, 2006.

Freeborn, P. H., Wooster, M. J., Malamud, B. D., Roberts, G., and $\mathrm{Xu}, \mathrm{W}$.: Development of a virtual active fire product for Africa through a synthesis of geostationary and polar orbiting satellite data, Remote. Sens. Environ, 2009.

Freeborn, P. H., Wooster, M. J., Hao, W. M., Ryan, C. A., Nordgren, B. L, Baker, S. P., and Ichoku, C.: Relationships between energy release, fuel mass loss, and trace gas and aerosol emissions during laboratory biomass fires, J. Geophys. Res., 113, D01301, doi:10.1029/2007JD008679, 2008.

Giglio, L., Descloitres, J., Justice, C. O., and Kaufman, Y. J.: An enhanced contextual fire detection algorithm for MODIS, Remote. Sens. Environ., 87, 2-3, 273-282, 2003.

Giglio, L., van der Werf, G. R., Randerson, J. T., Collatz, G. J., and
Kasibhatla, P.: Global estimation of burned area using MODIS active fire observations, Atmos. Chem. Phys., 6, 957-974, 2006, http://www.atmos-chem-phys.net/6/957/2006/.

Giglio, L., Csiszar, I., and Justice, C. O.: Global distribution and seasonality of active fires as observed with Terra and Aqua Moderate Resolution Imaging Spectroradiometers (MODIS) sensors, J. Geophys. Res., 111, G02016, doi:10.1029/2005JG000142, 2006 b.

Giglio, L.: Characterization of the tropical diurnal fire cycle using VIRS and MODIS observations, Remote. Sens. Environ., 108(4), 407-421, 2007.

Govaerts, Y. M., Pereira, J. M., Pinty, B., and Mota, B.: Impact of fires on surface albedo dynamics over the African continent, J. Geophys. Res., 107, 4629, doi:10.1029/2002JD002388, 2002.

Govender, N., Trollope, W. S. W., and van Wilgen, B. W.: The effect of fire season, fire frequency, rainfall and management on fire intensity in savanna vegetation in South Africa, J. Appl. Ecol., 43(4), 748-758, 2006.

Hansen, M. C., DeFries, R. S., Townshend, J. R. G., Carroll, M., Dimiceli, C., and Sohlberg, R. A.: Global Percent Tree Cover at a Spatial Resolution of 500 Meters: First Results of the MODIS Vegetation Continuous Fields Algorithm, Earth Interactions, 7(10), 1-15, 2003.

Hao, W. M., Ward, D, E., Olbu, G., and Baker, S. P.: Emissions of $\mathrm{CO}_{2}, \mathrm{CO}$ and hydrocarbons from fires in diverse African savanna ecosystems, J. Geophys. Res., 101(D19), 23577-23584, 1996.

Hoffa, E. A., Ward, D. E., Hao, W. M., Susott, R. A. and Wakimoto, R. H.: Seasonality of carbon emissions from biomass burning in a Zambian savanna, J. Geophys. Res., 104(D11), 13841-13853, 1999.

Holben, B. N., Setzer, A., Eck, T. F., Pereira, A. and Slutsker, I.: Effect of dry-season biomass burning on Amazon basin aerosol concentrations and optical properties 1992-1994, J. Geophys. Res., 101, 19465-19481, 1996.

Hyer, E. J., Kasischke, E. S., and Allen, D. J.: Effects of source temporal resolution on transport simulations of boreal fire emissions, J. Geophys. Res., 112, D01302, doi:10.1029/2006JD007234, 2007.

Ichoku, C., Giglio, L., Wooster, M. J., and Remer, L. A.: Global characterisation of biomass-burning patterns using satellite measurements of fire radiative energy, Remote. Sens. Environ., 112(6), 2950-2962, 2008.

IPCC (Intergovernmental Panel on Climate Change): In Third Assessment Report, Climate Change 2001, The Scientific Basis, Contribution of Working Group 1 to the Third Assessment Report of the Intergovernmental Panel on Climate Change (IPCC), Cambridge University Press, UK, 944 pp., 2001.

Ito, A. and Penner, J. E.: Global estimates of biomass burning emissions based on satellite imagery for the year 2000, J. Geophys. Res., 109, D14S05, doi:10.1029/2003/D004423, 2004.

Jost, C., Trentmann, J., Sprung, D., Andreae, M. O., McQuaid, J. B., and Barjat, H.: Trace gas chemistry in a young biomass burning plume over Namibia: Observations and model simulations, J. Geophys. Res., 108(D13), 8482, doi:10.1029/2002JD002431, 2003.

Korontzi, S.: Seasonal patterns of biomass burning emissions from Southern Africa vegetation fires for the year 2000, Glob. Change. Biol., 11(10), 1680-1700, 2005.

Korontzi, S., Roy, D. P., Justice, C. O., and Ward, D. E.: Model- 
ing and sensitivity analysis of fire emissions in Southern Africa during SAFARI 2000, Remote. Sens. Environ., 92(2), 376-396, 2004.

Lehsten, V., Tansey, K. J., Balzter, H., Thonicke, K., Spessa, A., Weber, U., Smith, B., and Arneth, A.: Estimating carbon emissions from African wildfires, Biogeosciences Discuss., 5, 30913122, 2008 ,

http://www.biogeosciences-discuss.net/5/3091/2008/.

Liu, J., Drummond, J. R., Li, Q., Gille, J. C., and Ziskin, D. C.: Satellite mapping of $\mathrm{CO}$ emission from forest fires in Northwest America using MOPITT measurements, Remote. Sens. Environ., 95, 502-516, 2005.

Mayaux, P., Bartholomé, E., Fritz, S., and Belward, A.: A new landcover map of Africa for the year 2000, J. Biogeogr., 31, 861-877, 2004.

Moula, M., Brustet, J. M. and Fontan, J.: Remote sensingmodelisation approach for diurnal estimation of burnt biomass in the Central African Republic savanna, J ATMOS CHEM , 25(1), 1-19, doi:10.1007/BF00053283, 1996.

Myneni, R. B. and Williams, D. L.: On the relationship between FAPAR and NDVI, Remote. Sens. Environ., 49(3), 200-211, 1994.

Pack, D. W., Rice, C. J., Tressel, B. J., Lee-Wagner, C. J., and Oshika, E. W.: Civilian uses of surveillance satellites, Crosslink, The Aerospace Corporation, 2-9, 2000.

Pétron, G., Granier, C., Khattatov, B., Yudin, V., Lamarque, J.-F., Emmons, L., Gille, J., and Edwards, D. P.: Monthly CO surface sources inventory based on the 20002001 MOPITT satellite data, Geophys. Res. Lett., 31, L21107, doi:10.1029/2004GL020560, 2004.

Plummer, S., Arino, O., Ranera, F., Tansey, K., Chen, J., Dedieu, G., Eva, H., Piccolini, I., Leigh, R., Borstlap, G., Beusen, B., Heyns, W., and Benedetti, R.: The GLOBCARBON Initiative: Global Biophysical Products for Terrestrial Carbon Studies, IEEE International Geoscience and Remote Sensing Symposium, Barcelona, Spain, 23-27 July 2007, 2007.

Prins, E. M. and Menzel, W. P.: Geostationary satellite detection of biomass burning in South America, Int. J. Remote. Sens., 13(15), 2783-2799, 1992.

Prins, E. M. and Menzel, W. P.: Trends in South American biomass burning with the GOES visible infrared spin scan radiometer atmospheric sounder from 1983 to 1991, J. Geophys. Res., 99, 16719-16735, 1994.

Prins, E. M., Feltz, J. M., Menzel, W. P. and Ward, D. E.: An overview of GOES-8 diurnal fire and smoke results for SCAR-B and 1995 fire season in South America, J. Geophys. Res., 103, 31821-31835, 1998.

Reid, J. S., Prins, E. M., Westphal, D. L., Schmidt, C. C., Richardson, K. A., Christopher, S. A., Eck, T. F., Reid, E. A., Curtis, C. A., and Hoffman, J. P.: Real-time monitoring of South American smoke particle emissions and transport using a coupled remote sensing/box-model approach, Geophys. Res. Lett., 31, L06107, doi:10.1029/2003GL018845, 2004.

Roberts, G., Wooster, M. J., Perry, G. L. W., Drake, N., Rebelo, L-M., and Dipotso, F.: Retrieval of biomass combustion rates and totals from fire radiative power observations: Application to Southern Africa using geostationary SEVIRI imagery, J. Geophys. Res., 110, D21111, doi:10.1029/2005JD006018, 2005.

Roberts, G. J. and Wooster. M. J.: Fire Detection and Fire Characterization over Africa using Meteosat SEVIRI, IEEE T. Geosci.
Remote., 46(4), 1200-1218, 2008.

Roy, D. P., Lewis, P. E., and Justice, C. O.: Burned area mapping using multi-temporal moderate spatial resolution data - A bi-directional reflectance model-based expectation approach, Remote. Sens. Environ., 83(1), 263-286, 2002.

Sá, A. C. L., Pereira, J. M. C., and Silva, J. M. N.: Estimation of combustion completeness based on fire-induced spectral reflectance changes in a dambo grassland (Western Province, Zambia), Int. J. Remote. Sens., 26(19), 4185-4195, 2005.

Scholes, R. J., Kendall, J., and Justice, C. O.: The quantity of biomass burned in Southern Africa, J. Geophys. Res., 101(D19), 23667-23676, 1996.

Schroeder, W., Csiszar, I., and Morisette, J.: Quantifying the impact of cloud obscuration on remote sensing of active fires in the Brazilian Amazon, Remote. Sens. Environ., 112(2), 456-470, 2008.

Shea, R. W., Shea, B. W., Kauffman, J. B., Ward, D. E., Haskins, C. I., and Scholes, M. C.: Fuel biomass and combustion factors associated with fires in savanna ecosystems of South Africa and Zambia, J. Geophys. Res., 101(D190), 23,551-23,569, 1996.

Simon, M., Plummer, S., Fierens, F., Hoelzemann, J. J., and Arino, O.: Burnt area detection at global scale using ATSR-2: The GLOBSCAR products and their qualification, J. Geophys. Res., 109, D14S02, doi:10.1029/2003JD003622, 2004.

Smith, A. M. S., Drake, N. A., Wooster, M. J., Hudak, A. T., Holden, Z. A., and Gibbons, C. J.: Production of Landsat ETM+ reference imagery of burned areas within Southern African savannahs: comparison of methods and application to MODIS, Int. J. Remote. Sens., 28(12), 2753-2775, 2007.

Swap, R. J., Annegarn, H. J., Suttles, J. T., King, M. D., Platnick, S., Privette, J. L., and Scholes, R. J.: Africa burning: A thematic analysis of the Southern African Regional Science Initiative (SAFARI 2000), J. Geophys. Res., 108.8465, doi:10.1029/2003JD003747, 2003.

Tansey, K., Grégoire, J.-M., Stroppiana, D., Sousa, A., Silva, J. M. N., Pereira, J. M. C., Boschetti, L., Maggi, M., Brivio, P. A., Fraser, R., Flasse, S., Ershov, D., Binaghi, E., Graetz, D., and Peduzzi, P.: Vegetation burning in the year 2000: Global burned area estimates from SPOT VEGETATION data, J. Geophys. Res., 109, D14S03, doi:10.1029/2003JD003598, 2004.

Trentmann, J., Andreae, M. O., Graf, H.-F., Hobbs, P. V., Ottmar, R. D., Trautmann, T. Simulation of a biomass-burning plume: Comparison of model results with observations, J. Geophys. Res., 107, 4013, doi:10.1029/2001JD000410, 2002.

van der Werf, G. R., Randerson, J. T., Collatz, G. J., and Giglio, L.: Carbon emissions from fires in tropical and subtropical ecosystems, Glob. Change. Biol., 9(40), 547-562, 2003.

van der Werf, G. R., Randerson, J. T., Giglio, L., Collatz, G. J., Kasibhatla, P. S., and Arellano Jr., A. F.: Interannual variability in biomass burning emissions from 1997 to 2004, Atmos. Chem. Phys. Discuss., 6, 3423-3441, 2006,

http://www.atmos-chem-phys-discuss.net/6/3423/2006/.

Veroustraete, F., Patyn, J., and Myneni, R. B.: Estimating net ecosystem exchange of carbon using the normalized difference vegetation index and an ecosystem model, Remote. Sens. Environ., 58(1), 115-130, 1996.

Ward, D. E., Hao, W. M., Susott, R. A, Babbitt, R. E., Shea, R. W., Kauffman, J. B., and Justice, C. O.: Effect of fuel composition on combustion efficiency and emission factors for African savanna 
ecosystems, J. Geophys. Res., 101(D19), 23569-23576, 1996.

Williams, C. A., Hanan, N. P., Neff, J. C., Scholes, R. J., Berry, J. A., Denning, A. S., and Baker, D. A.: Africa and the global carbon cycle, Carbon Balance and Management, 2(3), doi:10.1186/1750-0680-2-3, 2007.

Wittenberg, U., Heimann, M., Esser, G., McGuire, A. D. and Sauf, W.: On the influence of biomass burning on the seasonal $\mathrm{CO}_{2}$ signal as observed at monitoring stations, Global Biogeochem. Cy., 12(3), 531-544, 1998.

Wooster, M. J., Roberts, G., Perry, G. L. W. and Kaufman, Y. J.: Retrieval of biomass combustion rates and totals from fire radiative power observations: FRP derivation and calibration relationships between biomass consumption and fire radiative energy release, J. Geophys. Res., 110, D24311, doi:10.1029/2005JD006318, 2005.
Yevich, R. and Logan, J. A.: An assessment of biofuel use and burning of agricultural waste in the developing world, Global Biogeochem. Cy., 17(4), 1095, doi:10.1029/2002GB001952, 2003.

Zhang, Y.-H., Wooster, M. J., Tutubalina, O., and Perry, G. L. W.: Monthly burned area and forest fire carbon emission estimates for the Russian Federation from SPOT VGT, Remote. Sens. Environ., 87(1), 1-15, 2003. 